OPEN

SUBJECT AREAS:

COMPUTATIONAL

BIOPHYSICS

CALCIUM SIGNALLING

Received

29 July 2014

Accepted

24 December 2014

Published

23 January 2015

Correspondence and requests for materials should be addressed to

J.S. (jianweishuai@ xmu.edu.cn)

\section{Optimal microdomain crosstalk between endoplasmic reticulum and mitochondria for $\mathrm{Ca}^{2+}$ oscillations}

\author{
Hong Qi' , Linxi Li \& Jianwei Shuai ${ }^{1,2,3}$
}

'Department of Physics, Xiamen University, Xiamen 361005, China, ${ }^{2}$ State Key Laboratory of Cellular Stress Biology, Innovation Center for Cell Biology, Xiamen University, Xiamen 361005, China, ${ }^{3}$ Fujian Provincial Key Laboratory of Theoretical and Computational Chemistry, Xiamen University, Xiamen 361005, China.

$\mathrm{A} \mathrm{Ca}^{2+}$ signaling model is proposed to consider the crosstalk of $\mathrm{Ca}^{2+}$ ions between endoplasmic reticulum (ER) and mitochondria within microdomains around inositol 1, 4, 5-trisphosphate receptors $\left(\mathrm{IP}_{3} \mathrm{R}\right)$ and the mitochondrial $\mathrm{Ca}^{2+}$ uniporter (MCU). Our model predicts that there is a critical IP ${ }_{3} \mathrm{R}-\mathrm{MCU}$ distance at which $50 \%$ of the ER-released $\mathrm{Ca}^{2+}$ is taken up by mitochondria and that mitochondria modulate $\mathrm{Ca}^{2+}$ signals differently when outside of this critical distance. This study highlights the importance of the $\mathrm{IP}_{3} \mathrm{R}-\mathrm{MCU}$ distance on $\mathrm{Ca}^{2+}$ signaling dynamics. The model predicts that when MCU are too closely associated with $\mathrm{IP}_{3} \mathrm{Rs}$, the enhanced mitochondrial $\mathrm{Ca}^{2+}$ uptake will produce an increase of cytosolic $\mathrm{Ca}^{2+}$ spike amplitude. Notably, the model demonstrates the existence of an optimal IP ${ }_{3} \mathrm{R}-\mathrm{MCU}$ distance (30$85 \mathrm{~nm}$ ) for effective $\mathrm{Ca}^{2+}$ transfer and the successful generation of $\mathrm{Ca}^{2+}$ signals in healthy cells. We suggest that the space between the inner and outer mitochondria membranes provides a defense mechanism against occurrences of high $\left[\mathrm{Ca}^{2+}\right]_{\mathrm{Cy}}$. Our results also hint at a possible pathological mechanism in which abnormally high $\left[\mathrm{Ca}^{2+}\right]_{\mathrm{Cyt}}$ arises when the $\mathrm{IP}_{3} \mathrm{R}-\mathrm{MCU}$ distance is in excess of the optimal range.

r he calcium ion $\left(\mathrm{Ca}^{2+}\right)$ is a ubiquitous intracellular signal controlling diverse cellular functions, such as muscle cell contraction, neurotransmitter release from neurons and astrocytes, metabolic processes, egg activation, and cell maturation, differentiation and death ${ }^{1} . \mathrm{Ca}^{2+}$ signals commonly appear as repetitive spikes of cytosolic $\mathrm{Ca}^{2+}$ concentration $\left(\left[\mathrm{Ca}^{2+}\right]_{\mathrm{Cyt}}\right)$, with signaling information encoded in the frequency, amplitude and duration of these oscillations ${ }^{2}$. The complex spatial-temporal profiles of $\left[\mathrm{Ca}^{2+}\right]_{\mathrm{Cyt}}$ depend heavily on the endoplasmic reticulum (ER) and mitochondria ${ }^{3}$ which act as the two major intracellular $\mathrm{Ca}^{2+}$ stores.

While it has been widely accepted that the inositol 1, 4, 5-trisphosphate receptors $\left(\mathrm{IP}_{3} \mathrm{R}\right)$ function as $\mathrm{Ca}^{2+}$ release channels on the ER membrane ${ }^{1}$, mitochondria were previously considered only to function as $\mathrm{Ca}^{2+}$-sinks under pathological conditions when there is an abnormally high cellular $\mathrm{Ca}^{2+3}$. This view on mitochondria began to change in the 1990s with two landmark studies demonstrating that non-pathological elevations of $\left[\mathrm{Ca}^{2+}\right]_{\mathrm{Cyt}^{\mathrm{t}}}$ are accompanied by a marked rise of mitochondrial matrix $\mathrm{Ca}^{2+}$ concentrations $\left(\left[\mathrm{Ca}^{2+}\right]_{\mathrm{Mt}}\right)^{4}$ and that $\left[\mathrm{Ca}^{2+}\right]_{\mathrm{Mt}}$ responds dynamically to physiological oscillations of $\left[\mathrm{Ca}^{2+}\right]_{\mathrm{Cyt}}{ }^{5}$. Experimental observations indicated that mitochondria can accumulate $\mathrm{Ca}^{2+}$ through the mitochondrial $\mathrm{Ca}^{2+}$ uniporter (MCU) which is located on the inner mitochondrial membrane (IMM) $)^{6}$. In despite of its low $\mathrm{Ca}^{2+}$ affinity, the MCU is exposed to a high $\left[\mathrm{Ca}^{2+}\right]_{\mathrm{Cyt}}$ generated in microdomain around the channel pore of open $\mathrm{IP}_{3} \mathrm{Rs}^{7,8}$, thus even when global $\left[\mathrm{Ca}^{2+}\right]_{\mathrm{Cyt}}$ is low a high value of $\left[\mathrm{Ca}^{2+}\right]_{\mathrm{Mt}}$ may be observed. As a result, mitochondria can serve as buffers of cytoplasmic $\mathrm{Ca}^{2+}$ under both pathological and non-pathological conditions.

Although it is now generally believed that mitochondria function as a dynamic $\mathrm{Ca}^{2+}$ sequestration system to shape cytosolic $\mathrm{Ca}^{2+}$ oscillations, and therefore regulate many physiological processes ${ }^{6}$, the detailed mechanism underlying how mitochondria influence global $\mathrm{Ca}^{2+}$ signals remains elusive. Contradictory mechanisms have been suggested on how mitochondrial $\mathrm{Ca}^{2+}$ uptake regulates $\mathrm{IP}_{3} \mathrm{R}$ activity, including up-regulation ${ }^{9-11}$, downregulation ${ }^{12,13}$ and complete independence ${ }^{14}$. Furthermore, although mitochondrial $\mathrm{Ca}^{2+}$ uptake via MCU depends primarily on the spacing between the ER and mitochondria ${ }^{15}$, the working distance between the two organelles remains unclear due to the complexity of the intracellular environment and the lack of spatial resolution in the experimental observations. Indeed, the existing estimates of the distances between the ER and mitochondria vary hugely, from less than $10 \mathrm{~nm}$ to more than $200 \mathrm{~nm}^{16}$. A recent paper published in 
PNAS $^{17}$ even argued that the mitochondria may not act as a significant dynamic buffer of cytosolic $\mathrm{Ca}^{2+}$ under physiological conditions.

Computational models provide a valuable tool for understanding of the mechanisms underlying $\mathrm{Ca}^{2+}$ signal transduction ${ }^{18}$ and the dynamics of $\mathrm{Ca}^{2+}$ release from the ER has been extensively modeled ${ }^{19-23}$. Some models only focused on mitochondrial $\mathrm{Ca}^{2+}$ dynamics $^{24,25}$. Dash and co-workers developed a detailed kinetic model for MCU to match published data sets on mitochondrial $\mathrm{Ca}^{2+}$ uptake ${ }^{25}$. However, the involvement of both the ER and mitochondria in $\mathrm{Ca}^{2+}$ dynamics has only been considered in a limited number of models ${ }^{18,26-30}$. In the earlier models ${ }^{18,26}$, it was postulated that the MCU substantially sequesters $\mathrm{Ca}^{2+}$ when $\left[\mathrm{Ca}^{2+}\right]_{\text {Cyt }}<1 \mu \mathrm{M}$, in contrast to experimental evidence that the MCU actually sequesters $\mathrm{Ca}^{2+}$ in the range of $10-20 \mu \mathrm{M}^{3,31}$. Dupont et al. ${ }^{28}$ modeled the effect of Hint2, a mitochondrial protein, on cytosolic $\mathrm{Ca}^{2+}$ dynamics in hepatocytes. However, in these models the maximum value of ER luminal $\left[\mathrm{Ca}^{2+}\right]\left(\left[\mathrm{Ca}^{2+}\right]_{\mathrm{ER}}\right)$ is in the order of several to several tens of $\mu \mathrm{M}$, deviating drastically from most of the measured figures of 100$900 \mu \mathrm{M}^{32}$, and the value of $\left[\mathrm{Ca}^{2+}\right]_{\mathrm{Mt}}$ was also significantly underestimated. More importantly, except the model proposed by Szopa et al. ${ }^{29}$, none of them take into account the high $\left[\mathrm{Ca}^{2+}\right]_{\mathrm{Cyt}}$ microdomain, which is critical for mitochondrial $\mathrm{Ca}^{2+}$ signaling. The model considered by Szopa et al. $^{29}$ is a modification of the model from ref. 26, analyzing the influence of microdomain on the period and shape of calcium oscillations. They supposed that MCU sense elevated $\mathrm{Ca}^{2+}$ concentration which is directly equal to that in $\mathrm{ER}^{29}$. This assumption is incoherent with the experimental observation that $\left[\mathrm{Ca}^{2+}\right]_{\mathrm{Cyt}}$ in microdomain is about several tens of $\mu \mathrm{M}$, which is about 10-fold higher than that in the bulk cytosol ${ }^{7}$ and about 10 -fold lower than that in $\mathrm{ER}^{32}$. Thus, there is a lack of model to quantitatively investigate how the crosstalk between the ER and mitochondria controls $\mathrm{Ca}^{2+}$ signaling.

Here we consider a more realistic model to investigate the role of mitochondria in $\mathrm{Ca}^{2+}$ signaling to couple the ER and mitochondria based on the $\mathrm{Ca}^{2+}$ microdomain. A cytosolic microdomain is specifically considered in order to discuss the MCU dynamics and so each MCU specifically responds to the local high $\mathrm{Ca}^{2+}$ concentration in microdomain generated by a cluster of $\mathrm{IP}_{3} \mathrm{Rs}$. Our results demonstrate the critical role of mitochondrial $\mathrm{Ca}^{2+}$ uptake in modulating $\mathrm{IP}_{3} \mathrm{R}$-released $\mathrm{Ca}^{2+}$ signaling. We show that the location of the MCU relative to $\mathrm{IP}_{3} \mathrm{Rs}$ is a key determinant for modulating $\mathrm{Ca}^{2+}$ signals. There is a critical $\mathrm{IP}_{3} \mathrm{R}-\mathrm{MCU}$ distance at which $50 \%$ of the ERreleased $\mathrm{Ca}^{2+}$ is taken up by mitochondria and that mitochondria modulate $\mathrm{Ca}^{2+}$ signals differently when outside of this critical distance. When the $\mathrm{IP}_{3} \mathrm{R}-\mathrm{MCU}$ distance is greater than the critical distance mitochondrial $\mathrm{Ca}^{2+}$ uptake stimulates $\mathrm{ER}-\mathrm{Ca}^{2+}$ release by rapidly reducing the amplitude of the $\left[\mathrm{Ca}^{2+}\right]_{\mathrm{Cyt}}$ signal within the microdomain and suppressing the inhibition dynamics of high $\left[\mathrm{Ca}^{2+}\right]_{\mathrm{Cyt}}$ on $\mathrm{IP}_{3} \mathrm{R}$. However, when the distance is less than the critical distance, mitochondrial $\mathrm{Ca}^{2+}$ uptake demonstrates a different effect on $\mathrm{IP}_{3} \mathrm{R}$ dynamics. Initially strong mitochondrial uptake forces $\left[\mathrm{Ca}^{2+}\right]_{\mathrm{Cyt}}$ to a low level, thus preventing the strong activation dynamics of $\left[\mathrm{Ca}^{2+}\right]_{\text {Cyt }}$ on $\mathrm{IP}_{3} \mathrm{R}$. This leads to strong $\mathrm{IP}_{3} \mathrm{R}$ inhibition on the decay of subsequent $\left[\mathrm{Ca}^{2+}\right]_{\mathrm{Cyt}}$ spikes. Thus, our model predicts that when $\mathrm{MCU}$ are too closely associated with $\mathrm{IP}_{3} \mathrm{Rs}$, the enhanced mitochondrial $\mathrm{Ca}^{2+}$ uptake will produce an increase of cytosolic $\mathrm{Ca}^{2+}$ spike amplitude. As a result, there is an optimal spacing about 30-85 $\mathrm{nm}$ between the ER and mitochondria for generation of experimentally observed $\mathrm{Ca}^{2+}$ oscillations in living cells.

\section{Modelling coupled ER and mitochondria $\mathrm{Ca}^{2+}$ dynamics}

A "closed" cell model, which does not include $\mathrm{Ca}^{2+}$ exchange between cytosol and external medium through the plasma membrane, is considered to investigate the coupling effects between the
ER and mitochondria on $\mathrm{Ca}^{2+}$ signaling (Fig. 1(a)). As a result, the model has three compartments: cytosol (Cyt), ER and mitochondria (Mt). As shown in Fig. 1(a), the dynamics of the free $\left[\mathrm{Ca}^{2+}\right]$ in these compartments is determined by the $\mathrm{Ca}^{2+}$ fluxes from various channels and pumps and by buffering processes with various $\mathrm{Ca}^{2+}$ binding proteins $(\mathrm{BP})$, given by,

$$
\begin{aligned}
& \frac{\mathrm{d}\left[\mathrm{Ca}^{2+}\right]_{\mathrm{Cyt}}}{\mathrm{dt}}=\mathrm{j}_{\mathrm{ER}}^{\text {out }}-\mathrm{j}_{\mathrm{ER}}^{\text {in }}+\mathrm{j}_{\mathrm{Mt}}^{\text {out }}-\mathrm{j}_{\mathrm{Mt}}^{\text {in }}+\mathrm{j}_{\mathrm{CaCyt}}, \\
& \frac{\mathrm{d}\left[\mathrm{Ca}^{2+}\right]_{\mathrm{ER}}}{\mathrm{dt}}=\mathrm{V}_{\mathrm{Cyt}} / \mathrm{V}_{\mathrm{ER}}\left(\mathrm{j}_{\mathrm{ER}}^{\text {in }}-\mathrm{j}_{\mathrm{ER}}^{\text {out }}\right)+\mathrm{j}_{\mathrm{CaER}}, \\
& \frac{\mathrm{d}\left[\mathrm{Ca}^{2+}\right]_{\mathrm{Mt}}}{\mathrm{dt}}=\mathrm{V}_{\mathrm{Cyt}} / \mathrm{V}_{\mathrm{Mt}}\left(\mathrm{j}_{\mathrm{Mt}}^{\text {in }}-\mathrm{j}_{\mathrm{Mt}}^{\text {out }}\right)+\mathrm{j}_{\mathrm{CaMt}} .
\end{aligned}
$$

Here $\left[\mathrm{Ca}^{2+}\right]$ represents the free $\left[\mathrm{Ca}^{2+}\right], \mathrm{V}$ the volume of three compartments, $\mathrm{j}^{\text {in }}$ the $\mathrm{Ca}^{2+}$ flux from outside to inside, and $\mathrm{j}^{\text {out }}$ the opposite flux. The three terms $\mathrm{j}_{\mathrm{Ca}}$ represent $\mathrm{Ca}^{2+}$ dissociated from the BP.

In each compartment, $\mathrm{Ca}^{2+}$ can be buffered by various BPs. The kinetics between free $\mathrm{Ca}^{2+}$ and BP is described by a simple chemical reaction

$$
\mathrm{Ca}_{\mathrm{i}}+\mathrm{BP}_{\mathrm{i}} \underset{\mathrm{k}_{\text {offi }}}{\stackrel{\mathrm{k}_{\text {oni }}}{\rightleftharpoons}} \mathrm{CaBP} \mathrm{i}_{\mathrm{i}}, \quad \mathrm{i}=\mathrm{Cyt}, \mathrm{ER} \text { or } \mathrm{Mt}
$$

giving

$$
\mathrm{j}_{\text {Cai }}=\mathrm{k}_{\text {offi }}[\mathrm{CaBP}]_{\mathrm{i}}-\mathrm{k}_{\mathrm{oni}}\left[\mathrm{Ca}^{2+}\right]_{\mathrm{i}}\left([\mathrm{BP}]_{\mathrm{Tot}_{-} \mathrm{i}}-[\mathrm{CaBP}]_{\mathrm{i}}\right),
$$

where $[\mathrm{BP}]_{\text {Tot_i }}$ and $[\mathrm{CaBP}]_{\mathrm{i}}$ represent the total concentration of BP and the concentration of $\mathrm{Ca}^{2+}$-bound $\mathrm{BP}$ in each compartment, $\mathrm{k}_{\mathrm{on}}$ and $\mathrm{k}_{\text {off }}$ denote the on and off rate constants of $\mathrm{Ca}^{2+}$ with the $\mathrm{BP}$, respectively.

$\mathrm{Ca}^{2+}$ fluxes in ER component. The $\mathrm{Ca}^{2+}$ effluxes from the ER to cytosol are given by the $\mathrm{IP}_{3} \mathrm{R}$ release and a passive leakage with the concentration gradient across the ER membrane as their driving force, i.e.,

$$
\mathrm{j}_{\mathrm{ER}}^{\text {out }}=\left(\mathrm{v}_{\mathrm{IP}_{3} \mathrm{R}} \mathrm{P}_{\mathrm{oIP}_{3} \mathrm{R}}+\mathrm{c}_{\mathrm{Leak}}\right)\left(\left[\mathrm{Ca}^{2+}\right]_{\mathrm{ER}}-\left[\mathrm{Ca}^{2+}\right]_{\mathrm{Cyt}}\right),
$$

with $\mathrm{v}_{\text {IP3R }}$ being the maximal efflux from the $\mathrm{IP}_{3} \mathrm{Rs}$ in the ER membrane, $\mathrm{P}_{\text {oIP3R }}$ the open fraction of $\mathrm{IP}_{3} \mathrm{Rs}$, and $\mathrm{c}_{\text {Leak }}$ the $\mathrm{Ca}^{2+}$ leak constant.

The $\mathrm{IP}_{3} \mathrm{R}$ channel is an assembly of four equivalent subunits, each of which is mutually gated by $\mathrm{IP}_{3}$ and $\mathrm{Ca}^{2+}$. The gating dynamics of each $\mathrm{IP}_{3} \mathrm{R}$ subunit is described by the Li-Rinzel mode ${ }^{19}$ and we assumed that the channel is open if at least three of its subunits are in the active state ${ }^{20}$. Thus, we get the following expression for $\mathrm{P}_{\text {OIP3R: }}$

$$
\mathrm{P}_{\mathrm{oIP}_{3} \mathrm{R}}=\mathrm{s}_{\mathrm{act}}^{4}+4 \mathrm{~s}_{\mathrm{act}}^{3}\left(1-s_{\mathrm{act}}\right), \mathrm{s}_{\mathrm{act}}=\frac{\left[\mathrm{IP}_{3}\right]}{\left[\mathrm{IP}_{3}\right]+\mathrm{d}_{1}} \frac{\left[\mathrm{Ca}^{2+}\right]_{\mathrm{Cyt}}}{\left[\mathrm{Ca}^{2+}\right]_{\mathrm{Cyt}}+\mathrm{d}_{5}} \mathrm{~h} .
$$

Here $s_{a c t}$ is the probability in the active state of the subunit, $\left[\mathrm{IP}_{3}\right]$ is the $\mathrm{IP}_{3}$ concentration, and the slowly gating variable $\mathrm{h}$ is given by

$$
\frac{\mathrm{dh}}{\mathrm{dt}}=\alpha_{\mathrm{h}}(1-\mathrm{h})-\beta_{\mathrm{h}} \mathrm{h}, \alpha_{\mathrm{h}}=\mathrm{a}_{2} \mathrm{~d}_{2} \frac{\left[\mathrm{IP}_{3}\right]+\mathrm{d}_{1}}{\left[\mathrm{IP}_{3}\right]+\mathrm{d}_{3}}, \beta_{\mathrm{h}}=\mathrm{a}_{2}\left[\mathrm{Ca}^{2+}\right]_{\text {Cyt }},
$$

where $\mathrm{a}_{\mathrm{i}}$ and $\mathrm{d}_{\mathrm{i}}$ are constants.

The cytosolic $\mathrm{Ca}^{2+}$ can be pumped back into ER by active SERCA which is given by, 


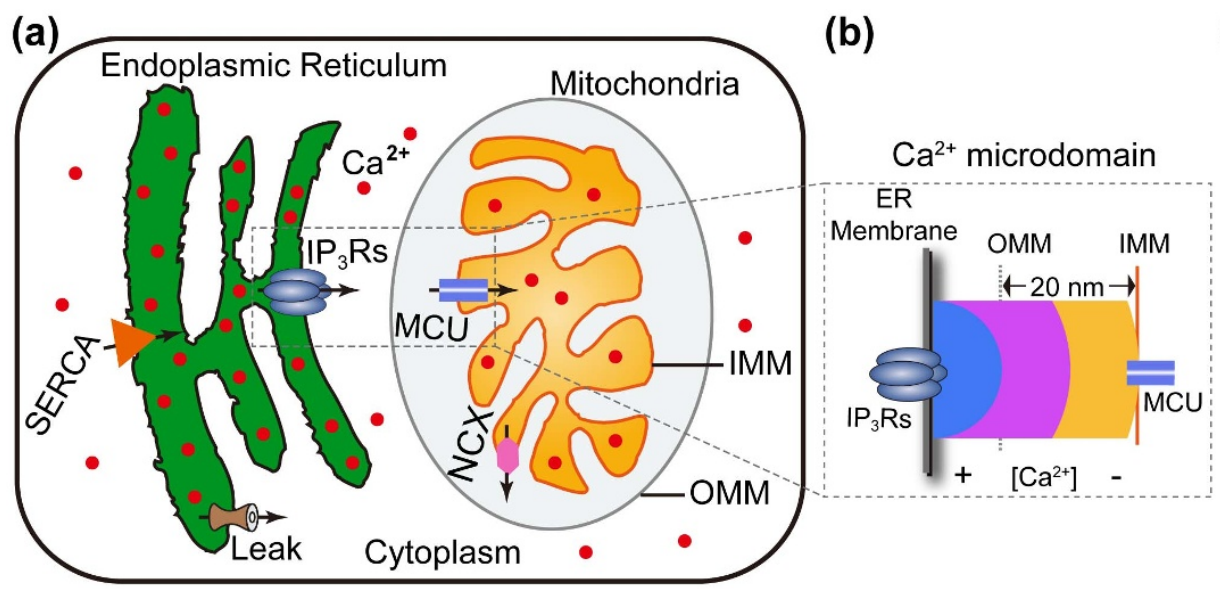

(c)

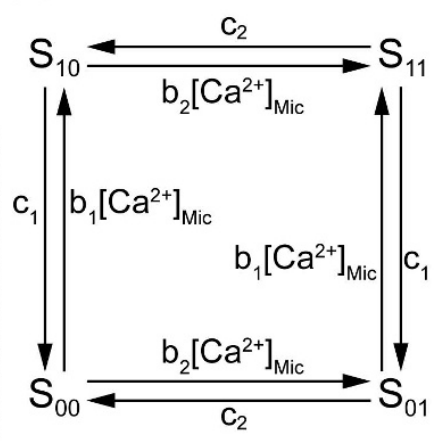

Figure $1 \mid$ The model design. (a) The schematic diagram of the components and fluxes included in the model. When a cell is stimulated to generate $\mathrm{IP}_{3}, \mathrm{IP}_{3}$ binds to $\mathrm{IP}_{3} \mathrm{R}$ and triggers $\mathrm{Ca}^{2+}$ release from the ER through $\mathrm{IP}_{3} \mathrm{Rs}$. The $\mathrm{Ca}^{2+}$ in the cytsol can be pumped back into ER by SERCA. (b) IP ${ }_{3} \mathrm{Rs}$ and MCUs in close proximity form a microdomain, a half 3-dimensional cytosolic space separated by ER membrane. A high microdomain $\left[\mathrm{Ca}^{2+}\right]\left(\left[\mathrm{Ca}^{2+}\right]_{\mathrm{Mic})}\right.$ can be generated upon opening of $\mathrm{IP}_{3} \mathrm{Rs}$ which in turn leads to $\mathrm{Ca}^{2+}$ uptake into mitochondria through MCUs. $\mathrm{Ca}^{2+}$ is extruded from mitochondria back into the cytosol by NCX. (c) The four-state model of MCU monomer with binding and unbinding rates.

$$
j_{\mathrm{ER}}^{\text {in }}=\frac{\mathrm{v}_{\text {SERCA }}\left[\mathrm{Ca}^{2+}\right]_{\mathrm{Cyt}}^{2}}{\mathrm{k}_{\mathrm{SERCA}}^{2}+\left[\mathrm{Ca}^{2+}\right]_{\mathrm{Cyt}}^{2}},
$$

where $\mathrm{v}_{\text {SERCA }}$ and $\mathrm{k}_{\text {SERCA }}$ are maximum SERCA pump flux and SERCA activation constants.

$\mathrm{Ca}^{2+}$ fluxes in mitochondrial component. Mitochondrial $\mathrm{Ca}^{2+}$ uptake through $\mathrm{MCU}$ is driven primarily by the large voltage across IMM. Besides the IMM voltage, it has been shown that MCU flux is also regulated by $\mathrm{MICU}^{33}$. For simplicity, in our model we only consider the role of MICU1 which has been well investigated in experiment. Then the MCU influx can be expressed as

$$
j_{\mathrm{Mt}}^{\text {in }}=\mathrm{v}_{\mathrm{MCU}} \Delta \Phi \mathrm{R}_{\mathrm{MICU}} \mathrm{P}_{\mathrm{oMCU}} \text {. }
$$

Here $\mathrm{v}_{\mathrm{MCU}}$ is the maximal flux of $\mathrm{MCU}, \Delta \Phi$ is the voltage driving force, $\mathrm{R}_{\mathrm{MICU}}$ represents the MICU1 regulatory term, and $\mathrm{P}_{\mathrm{OMCU}}$ describes the open fraction of MCU.

The IMM voltage $\Psi$ is $150 \sim 180 \mathrm{mV}$ (negative inside). Although the net $\mathrm{Ca}^{2+}$ flux into the mitochondria might associate with a reduction in voltage, some evidence suggests that mitochondrial $\mathrm{Ca}^{2+}$ uptake does not appear to alter $\Psi$ significantly during physiological condition ${ }^{34}$. With the assumption of constant $\Psi$, the driving force for MCU can be given by ${ }^{35}$

$$
\Delta \Phi=\frac{\mathrm{bF}\left(\psi-\psi_{0}\right)}{\mathrm{RT}} \mathrm{e}^{\frac{\mathrm{bF}\left(\psi-\psi_{0}\right)}{\mathrm{RT}}} \sinh \left(\frac{\mathrm{bF}\left(\psi-\psi_{0}\right)}{\mathrm{RT}}\right),
$$

Here F, R, and T are the Faraday constant, the gas constant and the Kelvin temperature, respectively; b and $\Psi_{0}$ are fitting parameters ${ }^{35}$.

As a regulatory subunit, MICU1 senses $\left[\mathrm{Ca}^{2+}\right]$ in mitochondrial intermembrane space to set a threshold for $\mathrm{MCU}^{33}$. The influx rate of MCU only becomes substantial when the extra-mitochondrial $\left[\mathrm{Ca}^{2+}\right]$ reaches values above $3 \mu \mathrm{M}^{36}$. As a result, the regulation of MICU1 to MCU activity has a sharp activation threshold ( $\left.\mathrm{k}_{\mathrm{MICU}}\right)$ with an apparent Hill coefficient equal to $4^{36}$ :

$$
\mathrm{R}_{\mathrm{MICU}}=\frac{\left[\mathrm{Ca}^{2+}\right]_{\mathrm{Mic}}^{4}}{\mathrm{k}_{\mathrm{MICU}}^{4}+\left[\mathrm{Ca}^{2+}\right]_{\mathrm{Mic}}^{4}},
$$

where $\left[\mathrm{Ca}^{2+}\right]_{\text {Mic }}$ is the microdomain $\left[\mathrm{Ca}^{2+}\right]_{\mathrm{Cyt}}$ that MCU is exposed to, which will be discussed later.
Whereas MICU1 acts as a regulator, MCU represents the core pore-forming component responsible for mitochondrial $\mathrm{Ca}^{2+}$ uptake ${ }^{37,38}$. Recent experimental and bioinformatic analysis reveals that MCU is an oligomer ${ }^{37}$ and most likely a tetramer ${ }^{39}$. Considering the biphasic dependence of $\mathrm{MCU}$ on $\left[\mathrm{Ca}^{2+}\right]_{\mathrm{Cyt}}$, i.e., fast $\mathrm{Ca}^{2+}$ -dependent activation and slow $\mathrm{Ca}^{2+}$-dependent inactivation of the $\mathrm{MCU}^{31}$, we simply propose that each monomer has two $\mathrm{Ca}^{2+}$ binding sites, one for activation and another for inhibition. Therefore a monomer can exist in 4 states of $\mathrm{s}_{00}, \mathrm{~s}_{10}, \mathrm{~s}_{01}$ and $\mathrm{s}_{11}$ with the first index for activation binding site and the second index for inhibition binding site and with 1 for binding and 0 unbinding (Fig. 1(c)). Similar as the $\mathrm{IP}_{3} \mathrm{R}$, we posit that the MCU is open if either 3 or 4 of the 4 monomers are in the active state $\left(\mathrm{s}_{10}\right)$. Thus, the MCU open fraction is given by,

$$
\mathrm{P}_{\mathrm{oMCU}}=\left(\mathrm{x}_{10}\right)^{4}+4\left(\mathrm{x}_{10}\right)^{3}\left(1-\mathrm{x}_{10}\right)
$$

where $\mathrm{x}_{\mathrm{ij}}$ denotes the probability of a monomer in states $s_{\mathrm{ij}}$. The dynamical equations governing the state of a monomer are

$$
\begin{gathered}
\frac{\mathrm{dx}_{00}}{\mathrm{dt}}=\left(\mathrm{c}_{2} \mathrm{x}_{01}-\mathrm{b}_{2}\left[\mathrm{Ca}^{2+}\right]_{\mathrm{Mic}} \mathrm{x}_{00}\right)-\left(\mathrm{b}_{1}\left[\mathrm{Ca}^{2+}\right]_{\mathrm{Mic}} \mathrm{x}_{00}-\mathrm{c}_{1} \mathrm{x}_{10}\right), \\
\frac{\mathrm{dx}_{10}}{\mathrm{dt}}=\left(\mathrm{b}_{1}\left[\mathrm{Ca}^{2+}\right]_{\mathrm{Mic}} \mathrm{x}_{00}-\mathrm{c}_{1} \mathrm{x}_{10}\right)-\left(\mathrm{b}_{2}\left[\mathrm{Ca}^{2+}\right]_{\mathrm{Mic}} \mathrm{x}_{10}-\mathrm{c}_{2} \mathrm{x}_{11}\right), \\
\frac{\mathrm{dx}_{01}}{\mathrm{dt}}=\left(\mathrm{c}_{1} \mathrm{x}_{11}-\mathrm{b}_{1}\left[\mathrm{Ca}^{2+}\right]_{\mathrm{Mic}} \mathrm{x}_{01}\right)-\left(\mathrm{c}_{2} \mathrm{x}_{01}-\mathrm{b}_{2}\left[\mathrm{Ca}^{2+}\right]_{\mathrm{Mic}} \mathrm{x}_{00}\right),
\end{gathered}
$$

with $\mathrm{x}_{00}+\mathrm{x}_{01}+\mathrm{x}_{10}+\mathrm{x}_{11}=1$.

$\mathrm{Ca}^{2+}$ is extruded from mitochondria primarily by NCX which swaps $3 \mathrm{Na}^{+}$ions with $1 \mathrm{Ca}^{2+}$ ion during each exchange cycle, Thus, the kinetic of outward calcium flux can be described $\mathrm{as}^{35}$

$$
\mathrm{j}_{\mathrm{Mt}}^{\text {out }}=\mathrm{v}_{\mathrm{NCX}} \frac{\left[\mathrm{Na}^{+}\right]_{\mathrm{Cyt}}^{3}}{\mathrm{k}_{\mathrm{Na}}^{3}+\left[\mathrm{Na}^{+}\right]_{\mathrm{Cyt}}^{3}} \frac{\left[\mathrm{Ca}^{2+}\right]_{\mathrm{Mt}}}{\mathrm{k}_{\mathrm{NCX}}+\left[\mathrm{Ca}^{2+}\right]_{\mathrm{Mt}}},
$$

where $\left[\mathrm{Na}^{+}\right]_{\text {Cyt }}$ is $\mathrm{Na}^{+}$concentration in the cytosol, $\mathrm{v}_{\mathrm{NCX}}$ is maximal NCX activity, both $\mathrm{k}_{\mathrm{Na}}$ and $\mathrm{k}_{\mathrm{NCX}}$ are activation constants for NCX.

Microdomain crosstalk between the ER and mitochondria. Now we describe a microdomain model that represents the crosstalk occurring between closely situated ER and mitochondria 
(Fig. 1(b)). The interacting players are $\mathrm{IP}_{3} \mathrm{Rs}$ and MCUs in the microdomain. A microdomain of local high $\left[\mathrm{Ca}^{2+}\right]_{\text {Cyt }}$ produced by nearby open $\mathrm{IP}_{3} \mathrm{Rs}$ is essential for high capacity $\mathrm{Ca}^{2+}$ transport into mitochondria via MCU. It has been reported that $90 \%$ of $\mathrm{IP}_{3} \mathrm{Rs}$ are located close to mitochondria and the majority of MCU sense the high $\left[\mathrm{Ca}^{2+}\right]_{\text {Mic }}$ in the vicinity of $\mathrm{IP}_{3} \mathrm{Rs}^{29}$. Here we make a specific assumption that MCU senses the local high $\left[\mathrm{Ca}^{2+}\right]_{\text {Mic }}$ generated by the opening of clustered $\mathrm{IP}_{3} \mathrm{Rs}$, but other $\mathrm{Ca}^{2+}$ handling components, such as $\mathrm{IP}_{3} \mathrm{Rs}$, SERCA, NCX, etc., are determined by the global averaged $\left[\mathrm{Ca}^{2+}\right]_{\mathrm{Cyt}}$. The pros and cons of our method will be discussed in the last section of the paper.

It has been suggested that each mitochondrial $\mathrm{Ca}^{2+}$ uptake site must face multiple $\mathrm{IP}_{3} \mathrm{Rs}$ for effective mitochondrial $\mathrm{Ca}^{2+}$ uptake ${ }^{40}$. Recent experiment evidence indicates that $\mathrm{IP}_{3} \mathrm{Rs}$ are typically distributed in clusters on the ER membrane, with each cluster containing a handful of $\mathrm{IP}_{3} \mathrm{Rs}^{41,42}$. Patch clamp experiments also show that the $\mathrm{Ca}^{2+}$ current $\left(\mathrm{I}_{\text {sIP3R }}\right)$ passing through a single open $\mathrm{IP}_{3} \mathrm{R}$ is linearly correlated with the concentration gradient $\left(\left[\mathrm{Ca}^{2+}\right]_{\mathrm{ER}}-\left[\mathrm{Ca}^{2+}\right]_{\mathrm{Cyt}}\right)$ across the ER membrane with a slope of $\mathrm{S}_{\mathrm{IP} 3 \mathrm{R}}=0.3 \mathrm{pA} / \mathrm{mM}^{43}$. Considering the closely distributed $\mathrm{IP}_{3} \mathrm{Rs}$, we treat the $\mathrm{Ca}^{2+}$ flux from clustered $\mathrm{IP}_{3} \mathrm{Rs}$ as a $\mathrm{Ca}^{2+}$ current from a point source at cluster center. As a result, an effective $\mathrm{Ca}^{2+}$ current from clustered $\mathrm{IP}_{3} \mathrm{Rs}$ is expressed as

$$
\delta=\mathrm{n}_{\mathrm{IP}_{3} \mathrm{R}} \mathrm{P}_{\mathrm{OIP}_{3} \mathrm{R}} \mathrm{I}_{\mathrm{SIP}_{3} \mathrm{R}}, \mathrm{I}_{\mathrm{SIP}_{3} \mathrm{R}}=\mathrm{S}_{\mathrm{IP}_{3} \mathrm{R}}\left(\left[\mathrm{Ca}^{2+}\right]_{\mathrm{ER}}-\left[\mathrm{Ca}^{2+}\right]_{\mathrm{Cyt}}\right) .
$$

Here, $P_{\text {oIP3R }}$ is the $\operatorname{IP}_{3} R$ open probability given by Eq. 6 and $n_{I P 3 R}$ is the $\mathrm{IP}_{3} \mathrm{R}$ number in a cluster. According to Ref. 41 , we consider a typical cluster with $\mathrm{n}_{\mathrm{IP} 3 \mathrm{R}}=4$. These $4 \mathrm{IP}_{3}$ Rs are in tight association, organized in a square pattern.

Around the center of $\mathrm{IP}_{3} \mathrm{R}$ cluster, the open $\mathrm{IP}_{3} \mathrm{Rs}$ will generate a very sharp distribution of $\left[\mathrm{Ca}^{2+}\right]_{C y t}$ due to rapid $\mathrm{Ca}^{2+}$ diffusion producing a microdomain of high $\left[\mathrm{Ca}^{2+}\right]_{\mathrm{Cyt}}$. Here we also assume that the ER membrane acts as a flat boundary to limit the $\mathrm{Ca}^{2+}$ diffusion in a half 3-dimensional space, i.e. the cytosolic microdomian (Fig. 1(b)). Using hemispherical symmetry of $\mathrm{Ca}^{2+}$ diffusion from a point release source, the sharp distribution around the release point can be established with a signal equation analogous to the linear cable equation $^{44,45}$. As a solution of the linearized reaction-diffusion equation, the microdomain $\left[\mathrm{Ca}^{2+}\right]$ is given by ${ }^{45}$

$$
\left[\mathrm{Ca}^{2+}\right]_{\mathrm{Mic}}=\frac{\delta}{4 \pi \mathrm{rFD}_{\mathrm{c}}} \mathrm{e}^{(-\mathrm{r} / \lambda)}+\left[\mathrm{Ca}^{2+}\right]_{\mathrm{Cyt}}
$$

with

$$
\lambda=\sqrt{\mathrm{D}_{\mathrm{c}} /\left(\mathrm{k}_{\mathrm{onCyt}}[\mathrm{BP}]_{\mathrm{Mic}} \mathrm{K}_{\mathrm{d}} /\left(\mathrm{K}_{\mathrm{d}}+\left[\mathrm{Ca}^{2+}\right]_{\mathrm{Cyt}}\right)\right)}
$$

Here, $D_{c}$ is the diffusion coefficient for free $\mathrm{Ca}^{2+}$. The parameter $\lambda$ is an important factor that determines the sharp decay of $\left[\mathrm{Ca}^{2+}\right]$ within a microdomain, which accounts for the $\mathrm{Ca}^{2+}$ diffusion and binding to BPs. $[\mathrm{BP}]_{\text {Mic }}$ is the total concentration of $\mathrm{BP}$ in the microdomain and $\mathrm{K}_{\mathrm{d}}$ is its dissociation constant ${ }^{44,45}$. One can see that the $\left[\mathrm{Ca}^{2+}\right]_{\mathrm{Mic}}$ within a microdomain becomes the cellular average $\left[\mathrm{Ca}^{2+}\right]_{\mathrm{Cyt}}$ when there are no open $\mathrm{IP}_{3} \mathrm{Rs}$.

Eq. 16 describes the $\left[\mathrm{Ca}^{2+}\right]$ distribution at distance $\mathrm{r}$ around the point source, i.e., the $\mathrm{IP}_{3} \mathrm{R}$ cluster center. In our model the parameter $r$ is the distance between the MCU and the $\mathrm{IP}_{3} \mathrm{R}$ cluster center, which we will call the $\mathrm{IP}_{3} \mathrm{R}-\mathrm{MCU}$ distance in the paper. Thus, $\left[\mathrm{Ca}^{2+}\right]_{\mathrm{Mic}}$ is the microdomain $\mathrm{Ca}^{2+}$ concentration that the $\mathrm{MCU}$ sees. Considering MCUs located on IMM, here we also simply assume that the outer mitochondrial membrane (OMM) has little effect on the $\mathrm{Ca}^{2+}$ diffusion as it has high permeability to $\mathrm{Ca}^{2+}{ }^{6}$. If we suppose the IMM and ER membrane are parallel, parameter $r$ also represents the distance between IMM and ER membrane. As a result, Eq. 16 represents the microdomain coupling between the ER and mitochondria in our model.

Parameter values. The parameters used in this model are listed in Table 1 (see supplementary material). They are categorized on the basis of their source to: (a) those extracted directly from experimental data; (b) those obtained from previously published models; or (c) the free parameters which were fit to experimental results. The model presented in this study permits simultaneous calculation of $\left[\mathrm{Ca}^{2+}\right]$ changes in the 3 compartments. Currently, it is difficult to measure experimentally $\mathrm{Ca}^{2+}$ concentrations in the cytosol and ER or mitochondria simultaneously because of the highly dynamic nature of the $\mathrm{Ca}^{2+}$ signals that occur within organelles ${ }^{46}$. Only a few existing experimental data sets ${ }^{46,47}$ consist of measurements from all 3 compartments. The free parameters used in our model were extrapolated from fits to these data sets.

\section{Results}

The $\mathrm{Ca}^{2+}$ oscillations. Our first priority was to determine whether the model realistically simulated cellular $\mathrm{Ca}^{2+}$ dynamics. As shown in Fig. $2 \mathrm{a}$, when setting $\left[\mathrm{IP}_{3}\right]=0.5 \mu \mathrm{M}$ our model generates baseline $\mathrm{Ca}^{2+}$ oscillations occurring as a series of discrete spikes. The values for basal and stimulated $\left[\mathrm{Ca}^{2+}\right]$ for the cytosol, mitochondria and ER in the model are in close accord with experimental data ${ }^{38,48}$. The oscillations period is in the order of several ten seconds, as seen in many experimental observations with non-exitable cells ${ }^{2,48}$. The $\mathrm{Ca}^{2+}$ spikes show relatively rapid rising phases and slow falling phases, mimicking those seen in experimental recordings ${ }^{49}$. The cytosolic and mitochondrial $\left[\mathrm{Ca}^{2+}\right]$ oscillate almost in phase, with $\left[\mathrm{Ca}^{2+}\right]_{\mathrm{Cyt}}$ as the leader, while the ER $\left[\mathrm{Ca}^{2+}\right]$ is in anti-phase with them, also as observed experimentally ${ }^{13,47}$.

Having established that the salient features of the $\mathrm{Ca}^{2+}$ dynamics of our model are in good agreement with existing experimental observations, we examined the effect of manipulating the mechanisms modulated by the crosstalk of the ER and mitochondria. Thus, we also performed simulations in which mitochondria were absent from the model (Fig. 2b). The minimal values of $\left[\mathrm{Ca}^{2+}\right]_{\mathrm{ER}}$ are $311 \mu \mathrm{M}$ and $276 \mu \mathrm{M}$ in the absence and in the presence of mitochondria, respectively (Fig. 2), indicating that more $\mathrm{Ca}^{2+}$ ions are released from the ER during each spiking cycle in the presence of mitochondria. The maximal values of $\left[\mathrm{Ca}^{2+}\right]_{\text {Cyt }}$ are $5.6 \mu \mathrm{M}$ and $2.5 \mu \mathrm{M}$ in the absence and in the presence of mitochondria, respectively (Fig. 2), showing that mitochondria can significantly decrease $\left[\mathrm{Ca}^{2+}\right]_{\text {Cyt }}$ oscillation amplitude.

$\mathrm{Ca}^{2+}$ oscillation modulated by $\mathrm{IP}_{3} \mathrm{R}-\mathrm{MCU}$ distance. Next we looked at the effect of $\mathrm{IP}_{3} \mathrm{R}-\mathrm{MCU}$ distance on $\mathrm{Ca}^{2+}$ oscillation in detail. Fig. 3 compares oscillating $\left[\mathrm{Ca}^{2+}\right]$ trajectories in microdomain, ER, mitochondria, and cytosol during a single cycle at varying $\mathrm{IP}_{3} \mathrm{R}-\mathrm{MCU}$ distances. By decreasing the $\mathrm{IP}_{3} \mathrm{R}-\mathrm{MCU}$ distance from infinity (we used simulations in which mitochondria were absent from the model as the infinite $\mathrm{IP}_{3} \mathrm{R}-\mathrm{MCU}$ distance), the $\left[\mathrm{Ca}^{2+}\right]_{\text {Mic }}$ in microdomain increases according to Eq. 16 against distance (Fig. 3a), giving an increase in mitochondrial $\mathrm{Ca}^{2+}$ uptake. As a result, the minimal $\left[\mathrm{Ca}^{2+}\right]_{\mathrm{ER}}$ steadily decreases (Fig. $3 \mathrm{~b}$ ) and the $\left[\mathrm{Ca}^{2+}\right]_{\mathrm{Mt}}$ spike amplitude steadily increases until saturating at about $65 \mu \mathrm{M}$ (Fig. 3c). However, an unexpected finding is that the $\left[\mathrm{Ca}^{2+}\right]_{\text {Cyt }}$ spike amplitude first decreases but then increases as the distance decreases (Fig. 3d).

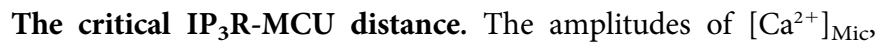
$\left[\mathrm{Ca}^{2+}\right]_{\mathrm{Mt}}$, and $\left[\mathrm{Ca}^{2+}\right]_{\mathrm{Cyt}}$ are plotted in detail as a function of distance from 10 to $150 \mathrm{~nm}$ at $\left[\mathrm{IP}_{3}\right]=0.5 \mu \mathrm{M}$ in Fig. $4 \mathrm{a}$ and $4 \mathrm{~b}$. A sharp increase is observed for $\left[\mathrm{Ca}^{2+}\right]_{\mathrm{Mic}}$ and $\left[\mathrm{Ca}^{2+}\right]_{\mathrm{Cyt}}$ at $\mathrm{r}<30 \mathrm{~nm}$, and $\left[\mathrm{Ca}^{2+}\right]_{\mathrm{Cyt}}$ reaches its minimum at $\mathrm{r}=30 \mathrm{~nm}$. Fig. $4 \mathrm{~b}$ also shows that the $\left[\mathrm{Ca}^{2+}\right]_{\mathrm{Cyt}}$ spiking period increases monotonically from 30 to 


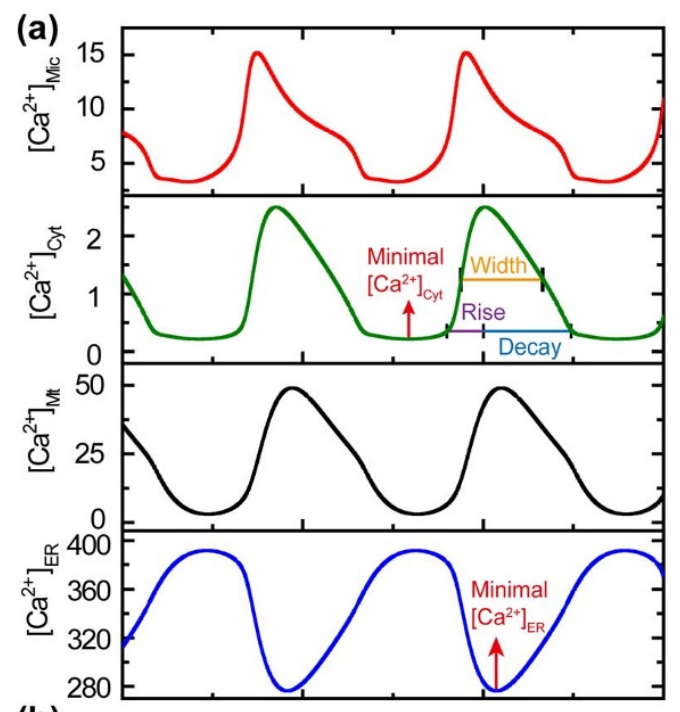

(b)

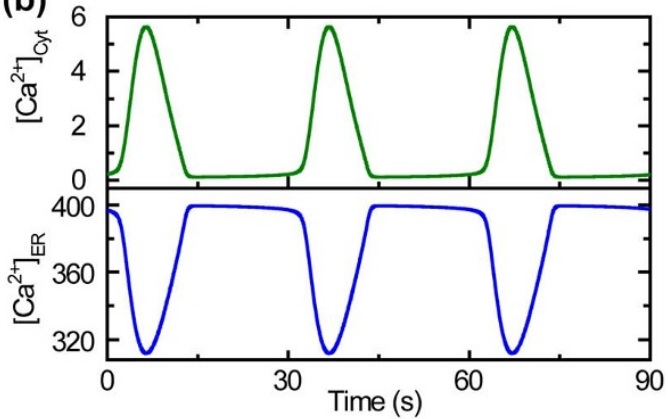

Figure $2 \mid$ Mitochondria serve as $\mathrm{Ca}^{2+}$ reservoirs. (a) Oscillations of: $\left[\mathrm{Ca}^{2+}\right]_{\mathrm{Mic}}$ in the $\mathrm{IP}_{3} \mathrm{R}-\mathrm{MCU}$ microdomain, $\left[\mathrm{Ca}^{2+}\right]_{\mathrm{Cyt}}$ in the cytosol, $\left[\mathrm{Ca}^{2+}\right]_{\mathrm{Mt}}$ in mitochondria, and $\left[\mathrm{Ca}^{2+}\right]_{\mathrm{ER}}$ in the ER in the presence of mitochondria with a $\mathrm{IP}_{3} \mathrm{R}-\mathrm{MCU}$ distance of $35 \mathrm{~nm}$. The width at half maximum, the rising duration and decay duration of $\left[\mathrm{Ca}^{2+}\right]_{\text {Cyt }}$ spike are marked in the second panel of (a). (b) Oscillations of: $\left[\mathrm{Ca}^{2+}\right]_{\mathrm{Cyt}}$ in the cytosol, and $\left[\mathrm{Ca}^{2+}\right]_{\mathrm{ER}}$ in the ER in the absence of mitochondria. $\left[\mathrm{IP}_{3}\right]=$ $0.5 \mu \mathrm{M}$. The unit of $\left[\mathrm{Ca}^{2+}\right]$ is $\mu \mathrm{M}$.

$50 \mathrm{sec}$, following the increased ability of mitochondria to take up $\mathrm{Ca}^{2+}$ as the $\mathrm{IP}_{3} \mathrm{R}-\mathrm{MCU}$ distance diminishes. The $\left[\mathrm{Ca}^{2+}\right]_{\text {Cyt }}$ spiking amplitude is determined by the number of $\mathrm{Ca}^{2+}$ ions that diffuse into the cytosol, which is related to the total amount of $\mathrm{Ca}^{2+}$ ions released from ER through $\mathrm{IP}_{3} \mathrm{Rs}$ and the fraction which are taken by mitochondria. In the model, the total amount of $\mathrm{Ca}^{2+}$ released from the ER through $\mathrm{IP}_{3} \mathrm{R}$ and the fraction accumulated by mitochondria through $\mathrm{MCU}$ during each oscillating cycle are plotted in Fig. $4 \mathrm{c}$ as a function of $\mathrm{IP}_{3} \mathrm{R}-\mathrm{MCU}$ distance. The fraction of mitochondrial $\mathrm{Ca}^{2+}$ uptake increases monotonically with decreasing distance indicating an increase in the ability of the mitochondria to take up $\mathrm{Ca}^{2+}$ at closer distances. Our simulation shows that at $30 \mathrm{~nm}$ distance, about $50 \%$ of the ER-released $\mathrm{Ca}^{2+}$ ions are taken up by mitochondria (see green line with stars in Fig. $4 \mathrm{c}$ ). As a consequence, $\mathrm{r}_{\mathrm{crt}}=30 \mathrm{~nm}$ acts as a critical distance for mitochondria to modulate cytosolic $\mathrm{Ca}^{2+}$ signaling: At $\mathrm{r}>\mathrm{r}_{\mathrm{cr}}$, more ER-released $\mathrm{Ca}^{2+}$ ions will diffuse into the cytosol than be taken up by mitochondria; whilst at $r<r_{\text {crt }}$, mitochondria will capture the majority of $\mathrm{Ca}^{2+}$ ions released from ER.

$\mathrm{Ca}^{2+}$ dynamics modulated by $\mathrm{IP}_{3} \mathrm{R}-\mathrm{MCU}$ distance. Surprisingly, Fig. $4 \mathrm{c}$ also shows another unexpected finding that the total amount of $\mathrm{Ca}^{2+}$ released from the ER first increases with distance down to $\mathrm{r}=20 \mathrm{~nm}$ and then decreases at smaller distance (see black line with squares in Fig. 4c). This raises a critical question: with decreasing distance at $\mathrm{r}<20 \mathrm{~nm}$, how can $\left[\mathrm{Ca}^{2+}\right]_{\mathrm{Cyt}}$ spiking amplitudes increase (violet line with diamonds in Fig. 4b), while the total amount of $\mathrm{Ca}^{2+}$ released from the ER decreases (black line with squares in Fig. 4c) but mitochondrial $\mathrm{Ca}^{2+}$ uptake fraction increases (green line with stars in Fig. 4c)?

In order to further examine this conflicting effect of distance on $\left[\mathrm{Ca}^{2+}\right]_{\mathrm{Cyt}}$ spike amplitude and the amount of ER-released $\mathrm{Ca}^{2+}$, we investigated how mitochondrial $\mathrm{Ca}^{2+}$ uptake modulates the spike width, the spike rising time and decay time of $\left[\mathrm{Ca}^{2+}\right]_{\mathrm{Cyt}}$ at varying $\mathrm{IP}_{3} \mathrm{R}-\mathrm{MCU}$ distance. Here the spike width is defined as the duration at half maximum of $\left[\mathrm{Ca}^{2+}\right]_{\mathrm{Cyt}}$ spike amplitude, the rising time is defined as the duration from twice of the minimal $\left[\mathrm{Ca}^{2+}\right]_{\mathrm{Cyt}}$ to the peak of the response, and the decay time as the duration from the peak of the response to twice of the minimal $\left[\mathrm{Ca}^{2+}\right]_{\mathrm{Cyt}}$. An example of definition of these parameters is marked in Fig. 2a for spike curve at distance $r=35 \mathrm{~nm}$.

We first discuss the simple situation at $r>r_{c r}$. As shown in Fig. $4 d$ when $r>r_{\text {crt }}$, the spike width increases with decreasing distance, which primarily arises from an increase in the duration of the decay time, whereas the rising time is rapid and shows little change with distance. As $\mathrm{r}$ decreases, the ability of mitochondrial $\mathrm{Ca}^{2+}$ uptake increases, leading to a decrease in $\left[\mathrm{Ca}^{2+}\right]_{\mathrm{Cyt}}$ amplitude. The decrease in $\left[\mathrm{Ca}^{2+}\right]_{\mathrm{Cyt}}$ amplitude in turn leads to a weakening of the $\mathrm{Ca}^{2+}$ inhibition of $\mathrm{IP}_{3} \mathrm{R}$ dynamics, resulting in the prolonged spike decay time with decreasing distance.

Differently, at $\mathrm{r}<\mathrm{r}_{\text {crt }}$, as the $\mathrm{IP}_{3} \mathrm{R}-\mathrm{MCU}$ distance decreases, even though the rising time increases (black line in Fig. 4d), the spike width actually becomes smaller due to a decrease in the decay time (blue and red lines in Fig. 4d). At this small distance, the rising time consists of both a slow rising phase and an abrupt rising phase. As an example, the slow rising and abrupt rising phases for a spike at distance $r=10 \mathrm{~nm}$ are indicated by arrows in Fig. 3a\&b. The mitochondrial $\mathrm{Ca}^{2+}$ uptake is so strong that, at the beginning of each oscillating cycle, most of the ER-released $\mathrm{Ca}^{2+}$ ions are directly driven into mitochondria, leading to a rapid increase of $\left[\mathrm{Ca}^{2+}\right]_{\mathrm{Mt}}$ (Fig. 3c), but a very slow increase of $\left[\mathrm{Ca}^{2+}\right]_{\text {Cyt }}$ (Fig. $3 \mathrm{~d}$ ). With low $\left[\mathrm{Ca}^{2+}\right]_{\mathrm{Cyt}}$, there are a small fraction of activating $\mathrm{IP}_{3} \mathrm{Rs}$ which remain open for a long time, resulting in a slow rise phase for $\left[\mathrm{Ca}^{2+}\right]_{\mathrm{Cyt}}$ (e.g. the gray dash line for $\mathrm{r}=10 \mathrm{~nm}$ in Fig. $3 \mathrm{~d}$ with time from 0 to $30 \mathrm{sec})$. Such a long duration with low $\left[\mathrm{Ca}^{2+}\right]_{\mathrm{Cyt}}$ actually contributes little to the spike width. When $\left[\mathrm{Ca}^{2+}\right]_{\mathrm{Mt}}$ increases to approach to its saturation state, most of the ER-released $\mathrm{Ca}^{2+}$ ions will then diffuse into cytosol. Because of the $\mathrm{Ca}^{2+}$ induced $\mathrm{Ca}^{2+}$ release, there occurs an abrupt increase in the numbers of open $\mathrm{IP}_{3} \mathrm{Rs}$, generating a spike (e.g. the gray dash line for $\mathrm{r}=10 \mathrm{~nm}$ in Fig. $3 \mathrm{~d}$ with time from 30 to $35 \mathrm{sec})$.

With shorter $\mathrm{IP}_{3} \mathrm{R}-\mathrm{MCU}$ distance, the mitochondria become more saturated prior to the abrupt rising phase, and thus during the abrupt rising phase the $\mathrm{Ca}^{2+}$ ions released from the ER diffuse more into cytosol, generating a higher amplitude spike in $\left[\mathrm{Ca}^{2+}\right]_{\mathrm{Cyt}}$ (violet line with diamonds in Fig. $4 \mathrm{~b}$ at $\mathrm{r}<30 \mathrm{~nm}$ ). In turn, the elevated $\left[\mathrm{Ca}^{2+}\right]_{\text {Cyt }}$ peak induces a strong inhibitory effect on $\mathrm{IP}_{3} \mathrm{R}$ dynamics, such that spikes decay faster as the $\mathrm{IP}_{3} \mathrm{R}-\mathrm{MCU}$ distance decreases (red line with circles in Fig. 4d).

The changes with distance seen in the amount of $\mathrm{Ca}^{2+}$ ions released from the ER during the rise and decay phases can then explain why the total amount of ER-released $\mathrm{Ca}^{2+}$ reaches a maximum around $r=20 \mathrm{~nm}$. At $r>r_{c r t}$, as the rising time is fast and little affected by distance (close to $6 \mathrm{~s}$ as shown in Fig. 4d), the elevation in the total amount of ER-released $\mathrm{Ca}^{2+}$ with decreasing distance mainly related to the increase of the decay phase. By decreasing $r$ at $r_{c r t}>r>20 \mathrm{~nm}$, although the amount of ER-released $\mathrm{Ca}^{2+}$ ions during the decay phase decreases because of the shortened decay duration (red line in Fig. 4d), the amount of ER-released $\mathrm{Ca}^{2+}$ ions during the rising phase increases because of the prolonged rising duration (black line in Fig. 4d). As a result, the total amount of $\mathrm{Ca}^{2+}$ 

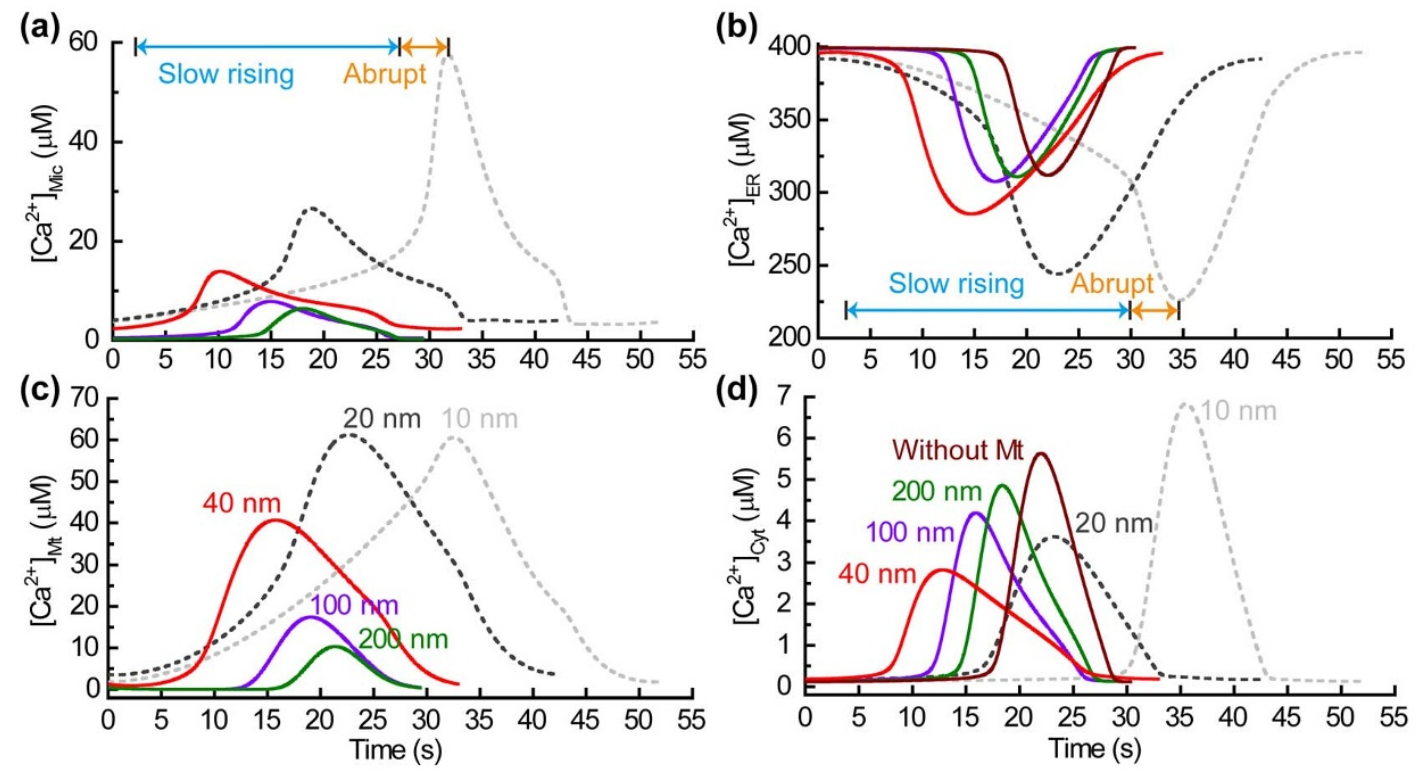

Figure $3 \mid$ The time evolution of $\left[\mathrm{Ca}^{2+}\right]_{\mathrm{Mic}}(\mathrm{a}),\left[\mathrm{Ca}^{2+}\right]_{\mathrm{ER}}(\mathrm{b}),\left[\mathrm{Ca}^{2+}\right]_{\mathrm{Mt}}(\mathrm{c})$ and $\left[\mathrm{Ca}^{2+}\right]_{\mathrm{Cyt}}(\mathrm{d})$ in an oscillating cycle at distance $\mathrm{r}=200(\mathrm{green}), 100$ (purple), 40 (red), 20 (dark) and $10 \mathrm{~nm}$ (grey). The brown lines in (b) and (d) are in the absence of mitochondria. In (a) and (b) the duration of an abrupt increase in $\mathrm{Ca}^{2+}$ release is marked by arrows for $\mathrm{r}=10 \mathrm{~nm}$. $\left[\mathrm{IP}_{3}\right]=0.5 \mu \mathrm{M}$.

released by ER keeps increasing with decreasing $\mathrm{r}$ for $\mathrm{r}_{\mathrm{crt}}>\mathrm{r}>$ $20 \mathrm{~nm}$. However, at very short distance of $\mathrm{r}<20 \mathrm{~nm}$, during the rising phase the ER-released $\mathrm{Ca}^{2+}$ ions almost saturate both mitochondria and the cytosol, giving a maximal $\mathrm{Ca}^{2+}$ amount released by ER during the rising phase (see the open circles in Fig. $4 \mathrm{c}$ at $\mathrm{r}<$ $20 \mathrm{~nm}$ ). Then, the change of the total amount of ER-released $\mathrm{Ca}^{2+}$ is typically determined by the change of decay time, leading to a decrease in the total amount of ER-released $\mathrm{Ca}^{2+}$ with decreasing distance at $\mathrm{r}<20 \mathrm{~nm}$.

Thus we can see how the apparently paradoxical relationship between $\left[\mathrm{Ca}^{2+}\right]_{\mathrm{Cyt}}$ spike amplitude and total amount of ER-released $\mathrm{Ca}^{2+}$ at $\mathrm{IP}_{3} \mathrm{R}-\mathrm{MCU}$ distances $<20 \mathrm{~nm}$ develops. At $\mathrm{r}<20 \mathrm{~nm}$, the
$\left[\mathrm{Ca}^{2+}\right]_{\mathrm{Cyt}}$ spike amplitude is mainly determined by the amount of $\mathrm{Ca}^{2+}$ released during the abrupt rising phase of a $\mathrm{Ca}^{2+}$ response, giving an increasing relationship with decreasing distance. In contrast to this, the change in the total amount of ER-released $\mathrm{Ca}^{2+}$ mainly follows the behavior of the spike decay time, giving a decreasing relationship with decreasing distance at $\mathrm{r}<20 \mathrm{~nm}$.

The synchronization of the oscillation phases between $\left[\mathrm{Ca}^{2+}\right]_{\mathrm{Cy}}$, $\left[\mathrm{Ca}^{2+}\right]_{\mathrm{ER}}$, and $\left[\mathrm{Ca}^{2+}\right]_{\mathrm{Mt}}$ is also modulated by the $\mathrm{IP}_{3} \mathrm{R}-\mathrm{MCU}$ distance. Our data (not shown here) indicate that at $\mathrm{r}>\mathrm{r}_{\mathrm{crt}},\left[\mathrm{Ca}^{2+}\right]_{\mathrm{Cyt}}$ peaks first, followed by $\left[\mathrm{Ca}^{2+}\right]_{\mathrm{ER}}$ minimum and then $\left[\mathrm{Ca}^{2+}\right]_{\mathrm{Mt}}$ peak, due to an increase of the amount of ER-released $\mathrm{Ca}^{2+}$ ions diffusing into the cytosol at greater distances. However, when $r<r_{\text {crt }}$, more ER-
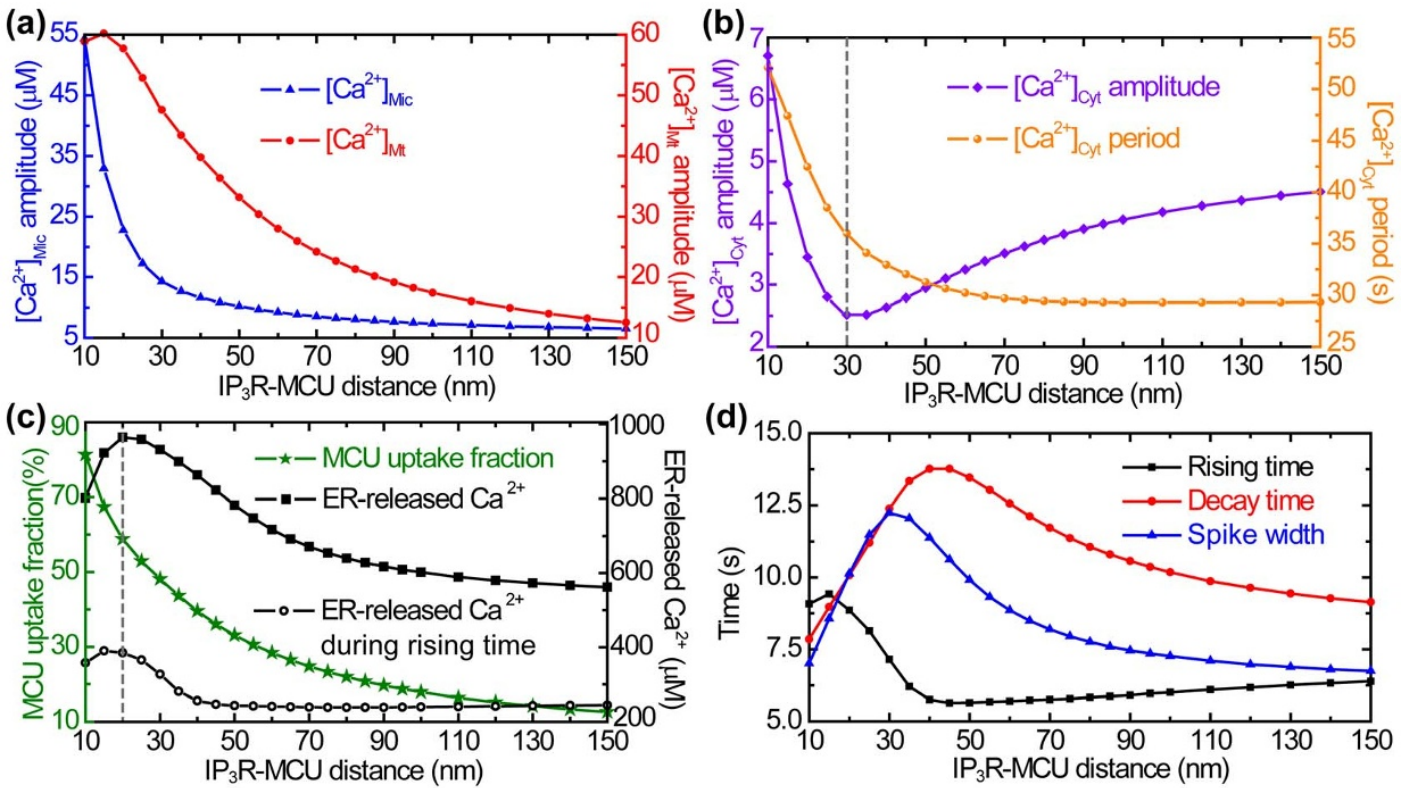

Figure $4 \mid \mathrm{Ca}^{2+}$ dynamics modulated by the $\mathrm{IP}_{3} \mathrm{R}-\mathrm{MCU}$ distance. (a) The spike amplitudes of $\left[\mathrm{Ca}^{2+}\right]_{\mathrm{Mic}}$ (triangles) and $\left[\mathrm{Ca}{ }^{2+}\right]_{\mathrm{Mt}}(\mathrm{circles})$. (b) The spike amplitudes of $\left[\mathrm{Ca}^{2+}\right]_{\mathrm{Cyt}}$ (diamonds) and spike period (spheres). (c) The total amount of $\mathrm{Ca}^{2+}$ released from the ER through IP ${ }_{3} \mathrm{Rs}$ during each cycle (squares), the amount of $\mathrm{Ca}^{2+}$ released from the ER through $\mathrm{IP}_{3} \mathrm{Rs}$ during the rising time (circles), and the fraction delivered to mitochondria through MCU (stars). (d) The spike width (triangles), the rising time (squares) and the decay time (circles) of $\left[\mathrm{Ca}^{2+}\right]_{\mathrm{Cyt}}$ oscillations. $\left[\mathrm{IP}_{3}\right]=0.5 \mu \mathrm{M}$. 

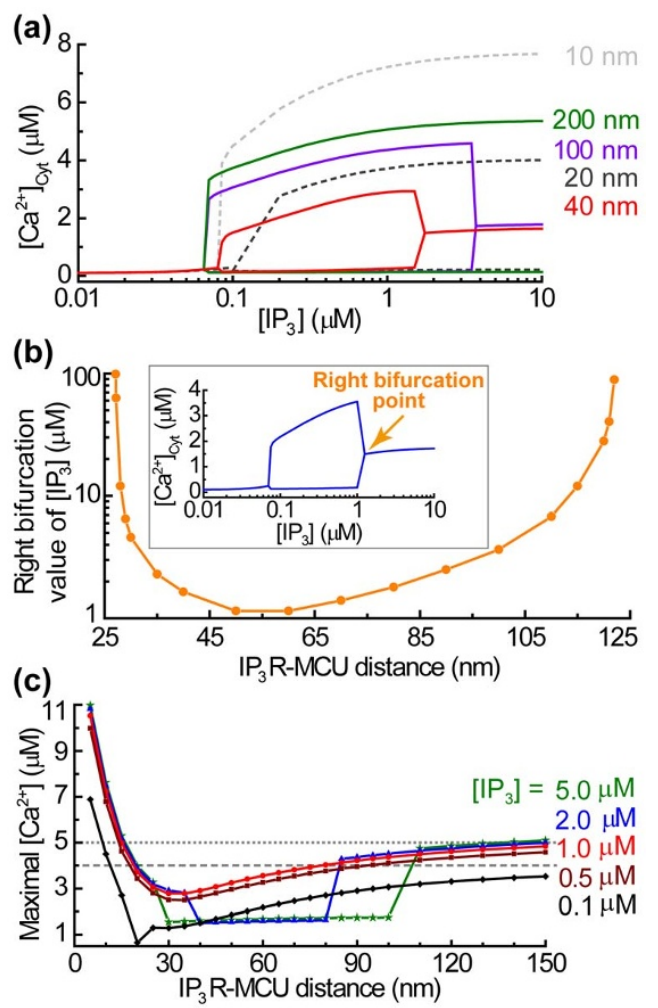

Figure $5 \mid \mathrm{Ca}^{2+}$ dynamics modulated by $\left[\mathrm{IP}_{3}\right]$. (a) The bifurcation diagram (the stable steady states and the maxima and minima of $\mathrm{Ca}^{2+}$ oscillations) of the model with $\left[\mathrm{IP}_{3}\right]$ as the bifurcation parameter at distance $\mathrm{r}=200$ (green), 100 (purple), 40 (red), 20 (dark) and $10 \mathrm{~nm}$ (grey). (b) The value of $\left[\mathrm{IP}_{3}\right]$ at the right bifurcation point plotted against distance. The inset is the bifurcation diagram at distance $r=60 \mathrm{~nm}$, in which the arrow marks the right bifurcation point. (c) The maximal $\left[\mathrm{Ca}^{2+}\right]_{\text {Cyt }}$ against the $\mathrm{IP}_{3} \mathrm{R}-\mathrm{MCU}$ distance for $\left[\mathrm{IP}_{3}\right]=0.1$ (lozenges), 0.5 (squares), 1.0 (circles), 2.0 (triangles), and $5.0 \mu \mathrm{M}$ (stars). The dashed and dotted lines represent $\left[\mathrm{Ca}^{2+}\right]_{\mathrm{Cyt}}=4$ and $5 \mu \mathrm{M}$, respectively.

released $\mathrm{Ca}^{2+}$ ions are sequestered into mitochondria, so $\left[\mathrm{Ca}^{2+}\right]_{\mathrm{Mt}}$ peaks first, followed by $\left[\mathrm{Ca}^{2+}\right]_{\mathrm{ER}}$ minimum and then $\left[\mathrm{Ca}^{2+}\right]_{\mathrm{Cyt}}$ peak.

$\mathrm{Ca}^{2+}$ dynamics modulated by [IP $\left.{ }_{3}\right]$. In the following discussion, we investigate how $\left[\mathrm{IP}_{3}\right]$ controlled $\left[\mathrm{Ca}^{2+}\right]_{\mathrm{Cyt}}$ oscillations can be modulated by the $\mathrm{IP}_{3} \mathrm{R}-\mathrm{MCU}$ distance. The bifurcation diagram for $\left[\mathrm{Ca}^{2+}\right]_{\text {Cyt }}$ oscillation (i.e. the steady state of $\left[\mathrm{Ca}^{2+}\right]_{\mathrm{Cyt}}$ or the maximum and minimum of $\left[\mathrm{Ca}^{2+}\right]_{\mathrm{Cyt}}$ oscillation) with $\left[\mathrm{IP}_{3}\right]$ as the bifurcation parameter is plotted at different $\mathrm{IP}_{3} \mathrm{R}-\mathrm{MCU}$ distances in Fig. 5a. When $\mathrm{IP}_{3}$ levels are low, $\left[\mathrm{Ca}^{2+}\right]_{\mathrm{Cyt}}$ can be seen to remain in a low stable steady state. Beyond a certain threshold value of $\left[\mathrm{IP}_{3}\right]$, $\left[\mathrm{Ca}^{2+}\right]_{\text {Cyt }}$ undergoes periodical oscillations. We also found that, at distance range of $27-122 \mathrm{~nm}$, the system only demonstrates sustained $\mathrm{Ca}^{2+}$ oscillations when $\left[\mathrm{IP}_{3}\right]$ values are in an intermediate range, evolving into a stable steady state at higher $\left[\mathrm{IP}_{3}\right]$ (Fig. 5b). Such a bifurcation diagram for $\mathrm{r}=60 \mathrm{~nm}$ is depicted in the inset of Fig. 5b. Similar bifurcation behavior has been observed in the experimental $\mathrm{Ca}^{2+}$ waves in Xenopus laevis oocytes. In oocytes it has been shown that repetitive $\mathrm{Ca}^{2+}$ waves occur only at intermediate $\left[\mathrm{IP}_{3}\right]$ between 0.1 and $1 \mu \mathrm{M}^{50}$. Thus, as shown in the inset of Fig. $5 b, r=60 \mathrm{~nm}$ is the optimum $\mathrm{IP}_{3} \mathrm{R}-\mathrm{MCU}$ distance in which our model replicates these experimental observations. According to the experiment ${ }^{50}$, for a biologically meaningful $\mathrm{Ca}^{2+}$ oscillation model there should be a right bifurcation point for high $\left[\mathrm{IP}_{3}\right]$, beyond which there occurs no $\mathrm{Ca}^{2+}$ oscillation. As plotted in Fig. 5b, only in the range of $\mathrm{r}$ of $27-$ $122 \mathrm{~nm}$ the model can produce $\mathrm{Ca}^{2+}$ oscillations in an intermediate
$\left[\mathrm{IP}_{3}\right]$ range. Outside of such distance range the $\mathrm{Ca}^{2+}$ oscillations always occur even at infinitely high $\left[\mathrm{IP}_{3}\right]$ (Fig. 5b).

$\left[\mathrm{Ca}^{2+}\right]_{\mathrm{Cyt}}$ oscillations with limited amplitudes regulate a host of vital cell functions ${ }^{1}$. A global $\left[\mathrm{Ca}^{2+}\right]_{\text {Cyt }}$ less than $3.5 \mu \mathrm{M}$ is usually observed in living cell ${ }^{38,48}$. However, high $\left[\mathrm{Ca}^{2+}\right]_{\text {Cyt }}$ will trigger and modulate apoptosis ${ }^{51}$. Fig. $5 c$ shows the maximal $\left[\mathrm{Ca}^{2+}\right]_{\mathrm{Cyt}}$ values seen in our model plotted against $\mathrm{IP}_{3} \mathrm{R}-\mathrm{MCU}$ distance for different $\left[\mathrm{IP}_{3}\right]$. One can see that a rapid elevation in $\left[\mathrm{Ca}^{2+}\right]_{\mathrm{Cyt}}$ amplitude is observed at $\mathrm{IP}_{3} \mathrm{R}-\mathrm{MCU}$ distances around $10 \mathrm{~nm}$. A global $\left[\mathrm{Ca}^{2+}\right]_{\mathrm{Cyt}}$ which is smaller than 4.0 or $5.0 \mu \mathrm{M}$ (i.e. dashed or dotted line in Fig. 5c) is typically obtained with $\mathrm{IP}_{3} \mathrm{R}-\mathrm{MCU}$ distances of 20 to $85 \mathrm{~nm}$ or distances of 15 to $150 \mathrm{~nm}$, respectively.

Robustness with varying clustered $I_{P_{3}} R$ number. In above study, we only consider a cluster in which $\mathrm{n}_{\mathrm{IP} 3 \mathrm{R}}=4 \mathrm{IP}_{3} \mathrm{Rs}$ correspond to a single MCU. Experimental evidence suggests that $\mathrm{IP}_{3} \mathrm{R}$ clusters typically contain a handful $(\sim 4)$ of $\mathrm{IP}_{3} \mathrm{Rs}^{41,42}$. Next we discuss the robustness of the model's behavior upon slight changes in $\mathrm{n}_{\mathrm{IP} 3 \mathrm{R}}$ (from 4 to 3 , and 5). By calculating the fraction of $\mathrm{Ca}^{2+}$ ions accumulated by mitochondria compared to the total amount of $\mathrm{Ca}^{2+}$ released from the ER, we see that the critical distance is changed to $20 \mathrm{~nm}$ for $\mathrm{n}_{\mathrm{IP} 3 \mathrm{R}}=3$ and $35 \mathrm{~nm}$ for $\mathrm{n}_{\mathrm{IP} 3 \mathrm{R}}=5$ (Fig. 6(a)). Fig. 6(b) gives the value of $\left[\mathrm{IP}_{3}\right]$ at the right bifurcation point against distance with varying $\mathrm{n}_{\mathrm{IP} 3 \mathrm{R}}$. A common region to find the right bifurcation $\left[\mathrm{IP}_{3}\right]$ is obtained with distances of 33 to $93 \mathrm{~nm}$. Fig. 6(c) shows the maximal $\left[\mathrm{Ca}^{2+}\right]_{\text {Cyt }}$ plotted against $\mathrm{IP}_{3} \mathrm{R}-\mathrm{MCU}$ distances for varying $\mathrm{n}_{\mathrm{IP} 3 \mathrm{R}}$. A global $\left[\mathrm{Ca}^{2+}\right]_{\text {Cyt }}$ which is smaller than 4.0 or $5.0 \mu \mathrm{M}$ (i.e. dashed or dotted line in Fig. 6(c)) is
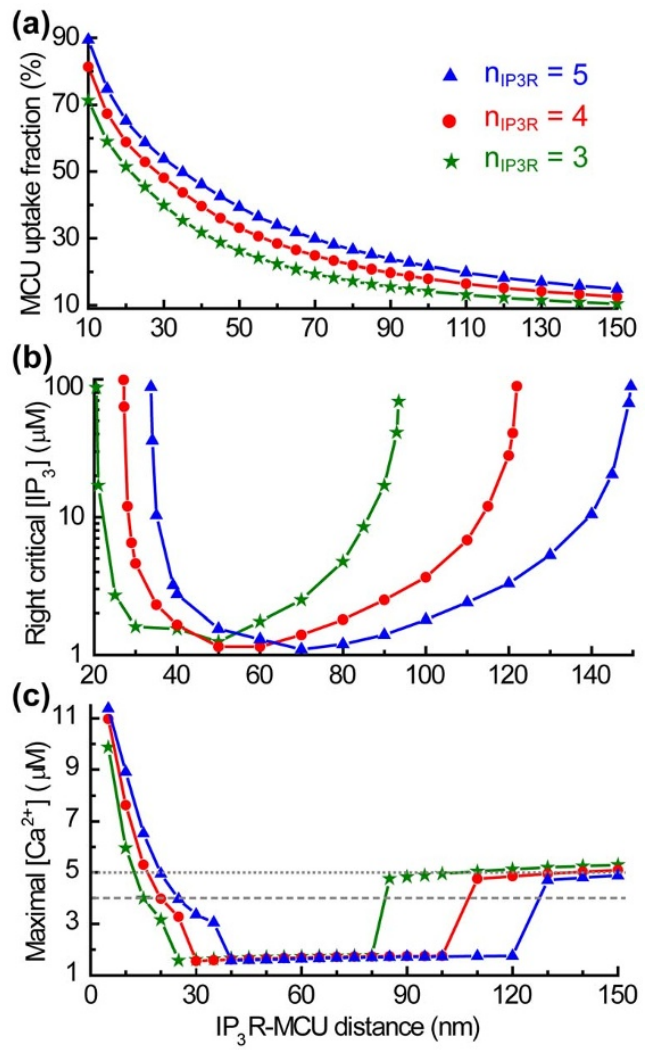

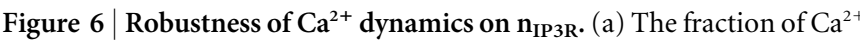
accumulated by mitochondria of the total amount of $\mathrm{Ca}^{2+}$ released from the ER during each oscillating cycle plotted against $\mathrm{IP}_{3} \mathrm{R}-\mathrm{MCU}$ distance. (b) The value of $\left[\mathrm{IP}_{3}\right]$ at the right bifurcation point against distance.

(c) The maximal $\left[\mathrm{Ca}^{2+}\right]_{\mathrm{Cyt}}$ against the $\mathrm{IP}_{3} \mathrm{R}-\mathrm{MCU}$ distance at saturating $\left[\mathrm{IP}_{3}\right]=5.0 \mu \mathrm{M}$. The dashed and dotted lines represent $\left[\mathrm{Ca}^{2+}\right]_{\mathrm{Cyt}}=4$ and $5 \mu \mathrm{M}$, respectively. Here $\mathrm{n}_{\mathrm{IP} 3 \mathrm{R}}=3$ (stars), 4 (circles) and 5 (triangles). 
typically obtained with $\mathrm{IP}_{3} \mathrm{R}-\mathrm{MCU}$ distances of 25 to $85 \mathrm{~nm}$ or distances of 20 to $110 \mathrm{~nm}$, respectively.

Taken together, compared with experimental observations $s^{38,48,50,51}$, the simulation results shown in Fig. 5 and Fig. 6 suggest that the optimal $\mathrm{IP}_{3} \mathrm{R}-\mathrm{MCU}$ distance for physiological $\mathrm{Ca}^{2+}$ signaling should be around 30 to $85 \mathrm{~nm}$. When the $\mathrm{IP}_{3} \mathrm{R}-\mathrm{MCU}$ distance is between 30 and $85 \mathrm{~nm}$, as illustrated in Fig. 6(a) approximately 15-55\% of ERreleased $\mathrm{Ca}^{2+}$ ions can be taken up by mitochondria, compatible with experimental measurements made in various cells ${ }^{52,53}$. Our model thus suggests that mitochondria, typically working at a short distance from the ER (but larger than $\mathrm{r}_{\mathrm{crt}}$ ), serve as $\mathrm{Ca}^{2+}$ sinks, sequestering $\mathrm{Ca}^{2+}$ ions released from the ER.

\section{Discussion}

Since the 1990s, the manner in which mitochondrial $\mathrm{Ca}^{2+}$ uptake through MCU shapes intracellular $\mathrm{Ca}^{2+}$ signaling has attracted much attention ${ }^{6}$. The key questions presently debated are: to what extent mitochondria acquire $\mathrm{Ca}^{2+}$; what impact mitochondria have on cytosolic $\mathrm{Ca}^{2+}$ signals; and what dimensions the ER/mitochondria $\mathrm{Ca}^{2+}$ microdomain might have. To address these questions, we constructed a $\mathrm{Ca}^{2+}$ signaling model to consider the $\mathrm{Ca}^{2+}$ crosstalk within microdomains between $\mathrm{IP}_{3}$ Rs and MCU. A 4-states MCU model has been suggested based on the latest experimental results ${ }^{31,37-39}$. The MCU is exposed to the microdomain $\mathrm{Ca}^{2+}$ concentration which is released from the nearby clustered $\mathrm{IP}_{3} \mathrm{Rs}^{34,36}$, rather than the bulk cytosolic $\mathrm{Ca}^{2+}$ concentration. As a result, the model replicates the shape, amplitude, period, and kinetics of the $\mathrm{Ca}^{2+}$ spikes observed in experimental data, allowing us to examine the effects of mitochondrial $\mathrm{Ca}^{2+}$ uptake on cytosolic $\mathrm{Ca}^{2+}$ signals.

From experimental observations, it has been suggested that mitochondrial $\mathrm{Ca}^{2+}$ uptake contributes significantly to the physiological regulation of cytosolic $\mathrm{Ca}^{2+38}$. Regarding the recent controversy whether mitochondria act as significant buffers to cytosolic $\mathrm{Ca}^{2+}$ under physiological conditions ${ }^{17}$, our model indicates that mitochondria can accumulate large quantities of $\mathrm{Ca}^{2+}$ under physiological conditions (about 15-55\% of the total released from the ER) at $\mathrm{IP}_{3} \mathrm{R}-\mathrm{MCU}$ distances of $30-85 \mathrm{~nm}$. Furthermore, our model indicates that the distance between the ER and mitochondria appears to be an important factor in modulating $\mathrm{Ca}^{2+}$ signaling, especially considering that mitochondria can be highly mobile organelles ${ }^{54}$. There is a critical $\mathrm{IP}_{3} \mathrm{R}-\mathrm{MCU}$ distance $\mathrm{r}_{\text {crt }}$ (around 20 to $35 \mathrm{~nm}$ depending on $\mathrm{n}_{\mathrm{IP} 3 \mathrm{R}}$ ) at which half of the $\mathrm{Ca}^{2+}$ released by the ER is taken up by mitochondria. At distances smaller than $r_{c r t}$ mitochondria can take up more $\mathrm{Ca}^{2+}$, while at distances larger than $\mathrm{r}_{\mathrm{crt}}$, more $\mathrm{Ca}^{2+}$ ions diffuse from the ER into the cytosol. This leads to mitochondria displaying different kinds of $\mathrm{Ca}^{2+}$ signal modulation depending on their distance from the ER. The effects of mitochondria on the spike amplitude, spike width, and rising and decay time of $\left[\mathrm{Ca}^{2+}\right]_{\mathrm{Cyt}}$ spikes, the synchronization phase among $\left[\mathrm{Ca}^{2+}\right]_{\mathrm{Cyt}}$, $\left[\mathrm{Ca}^{2+}\right]_{\mathrm{ER}}$ and $\left[\mathrm{Ca}^{2+}\right]_{\mathrm{Mt}}$, and the total amount of $\mathrm{Ca}^{2+}$ released from the ER are all substantially modulated by how the $\mathrm{IP}_{3} \mathrm{R}-\mathrm{MCU}$ distance deviates from this critical value.

To explore experimentally the consequences of mitochondrial $\mathrm{Ca}^{2+}$ uptake on global $\mathrm{Ca}^{2+}$ signals, mitochondrial $\mathrm{Ca}^{2+}$ uptake is often prevented directly by applying an MCU inhibitor ${ }^{14}$ or modulated by using agents which either depolarize or hyperpolarize the mitochondrial membrane potential and thus dissipate or increase the driving force for $\mathrm{Ca}^{2+}$ uptake into the organelle $e^{10,14}$. How mitochondrial $\mathrm{Ca}^{2+}$ uptake affects $\mathrm{IP}_{3} \mathrm{R}$ release mechanism is still under investigation. Some researchers have argued that mitochondrial $\mathrm{Ca}^{2+}$ uptake may provide a positive modulation of $\mathrm{Ca}^{2+}$ release by suppressing the negative feedback of high $\left[\mathrm{Ca}^{2+}\right]_{\mathrm{Cyt}}$ on $\mathrm{IP}_{3} \mathrm{R}^{9-11}$. Others have suggested that mitochondrial $\mathrm{Ca}^{2+}$ uptake exerts a negative control on $\left[\mathrm{Ca}^{2+}\right]_{\text {Cyt }}$ by preventing the positive feedback of $\mathrm{Ca}^{2+}$ on $\mathrm{IP}_{3} \mathrm{R}^{12,13}$.

In our simulations, the ability of mitochondria to take up $\mathrm{Ca}^{2+}$ is changed by varying the $\mathrm{IP}_{3} \mathrm{R}-\mathrm{MCU}$ distance and so the mitochondrial modulation on $\mathrm{IP}_{3} \mathrm{R}$ dynamics has been examined. Our model indicates that altering mitochondrial $\mathrm{Ca}^{2+}$ uptake induces a nontrivial change on $\left[\mathrm{Ca}^{2+}\right]_{\mathrm{Cyt}}$ amplitude, which can reconcile the conflicting results of the change of $\left[\mathrm{Ca}^{2+}\right]_{\mathrm{Cyt}}$ amplitude observed in various experiments $^{9-13}$. When $\mathrm{IP}_{3} \mathrm{R}-\mathrm{MCU}$ distance is larger than the critical distance $\mathrm{r}_{\mathrm{crt}}$, mitochondrial $\mathrm{Ca}^{2+}$ uptake is weak and more $\mathrm{Ca}^{2+}$ ions diffuse into cytosol, the enhancement of mitochondrial $\mathrm{Ca}^{2+}$ uptake causes a decreasing $\left[\mathrm{Ca}^{2+}\right]_{\mathrm{Cyt}}$ spike peak, exerting a weakened inhibition effect on $\mathrm{IP}_{3} \mathrm{R}$ dynamics, resulting in a prolonged decay time of spikes. Thus, at this region, mitochondrial $\mathrm{Ca}^{2+}$ uptake offers a positive modulation of $\mathrm{Ca}^{2+}$ release by reducing $\left[\mathrm{Ca}^{2+}\right]_{\mathrm{Cyt}}$ amplitude to suppress the inhibition dynamics (i.e. the negative feedback) of high $\left[\mathrm{Ca}^{2+}\right]_{\mathrm{Cyt}}$ on $\mathrm{IP}_{3} \mathrm{R}$ during decay time of spikes (Fig. 7), similar as suggested in refs $9,10,11$. While, when $\mathrm{IP}_{3} \mathrm{R}-\mathrm{MCU}$ distance is smaller than the critical distance, mitochondria take more $\mathrm{Ca}^{2+}$ ions than those diffusing into cytosol, the strong mitochondrial $\mathrm{Ca}^{2+}$ uptake will force $\left[\mathrm{Ca}^{2+}\right]_{\mathrm{Cyt}}$ at a small value to prevent the strong activation

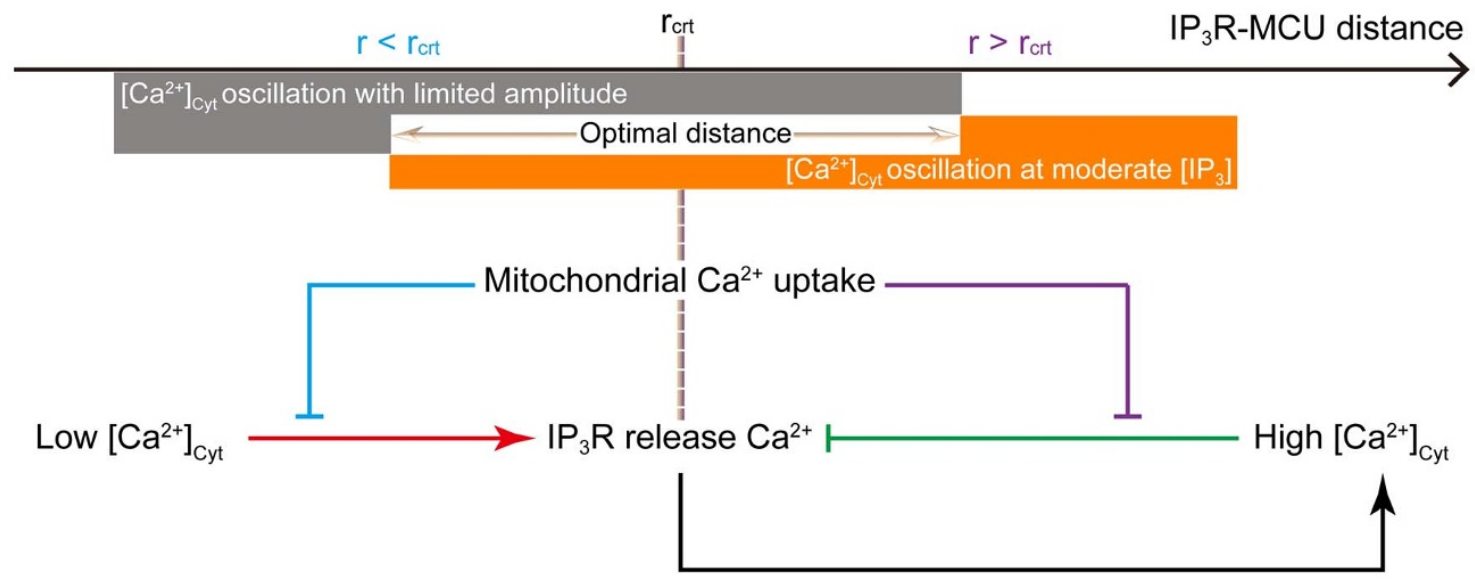

Figure 7 Schematic representation of how mitochondria modulate $\left[\mathrm{Ca}^{2+}\right]_{\mathrm{Cyt}} . \mathrm{IP}_{3} \mathrm{R}$ channel is regulated by $\mathrm{Ca}^{2+}$ in a biphasic manner: a lower $\left[\mathrm{Ca}^{2+}\right]_{\mathrm{Cyt}}$ promotes $\mathrm{Ca}^{2+}$ release and causes its elevation whereas higher $\left[\mathrm{Ca}^{2+}\right]_{\text {Cyt }}$ inhibits $\mathrm{Ca}^{2+}$ release. There is a critical distance at which $50 \%$ of the $\mathrm{IP}_{3} \mathrm{R}-\mathrm{released}$ $\mathrm{Ca}^{2+}$ ions are taken up by mitochondria. When $\mathrm{r}<\mathrm{r}_{\mathrm{crt}}$, mitochondrial $\mathrm{Ca}^{2+}$ uptake exerts a negative control on $\mathrm{IP}_{3} \mathrm{R}$-released $\mathrm{Ca}^{2+}$ by preventing the positive effect of low $\left[\mathrm{Ca}^{2+}\right]_{\mathrm{Cyt}}$ on $\mathrm{IP}_{3} \mathrm{R}$; whilst when $\mathrm{r}>\mathrm{r}_{\mathrm{crt}}$, mitochondrial $\mathrm{Ca}^{2+}$ uptake provides a positive modulation on $\mathrm{IP}_{3} \mathrm{R}-\mathrm{released} \mathrm{Ca}^{2+}$ by suppressing the negative effect of high $\left[\mathrm{Ca}^{2+}\right]_{\mathrm{Cyt}}$ on $\mathrm{IP}_{3} \mathrm{R}$. $\mathrm{Ca}^{2+}$ oscillations merely occur for moderate values of $\left[\mathrm{IP}_{3}\right]$ (orange range) with physiological amplitude (gray range), so the optimal distance of $\mathrm{IP}_{3} \mathrm{R}-\mathrm{MCU}$ should be within the intersection zone between the gray and orange range. 
dynamics (i.e. the positive feedback) of $\left[\mathrm{Ca}^{2+}\right]_{\mathrm{Cyt}}$ on $\mathrm{IP}_{3} \mathrm{R}$ (Fig. 7), similar as proposed in refs 12,13 . Thus, our model shows that this weak activation effect causes a small $\mathrm{Ca}^{2+}$ release from ER, giving a slow rising phase. When mitochondria approach to saturation and $\left[\mathrm{Ca}^{2+}\right]_{\mathrm{Cyt}}$ increases beyond the threshold of excitable dynamics, an abrupt rising phase occurs to generate a $\left[\mathrm{Ca}^{2+}\right]_{\mathrm{Cyt}}$ spike, giving a high $\left[\mathrm{Ca}^{2+}\right]_{\mathrm{Cyt}}$ amplitude and then inducing a strong inhibitory effect on $\mathrm{IP}_{3} \mathrm{R}$ dynamics to shorten the decay time of spikes.

An unexpected prediction with the model is that when the $\mathrm{IP}_{3} \mathrm{R}$ MCU distance is less than the critical distance, even though mitochondrial $\mathrm{Ca}^{2+}$ uptake keeps increasing with decreasing distance, the total amount of $\mathrm{Ca}^{2+}$ released from the ER decreases while the cytosolic $\mathrm{Ca}^{2+}$ spike amplitude increases. The $\left[\mathrm{Ca}^{2+}\right]_{\mathrm{Cyt}}$ peak is mainly determined by the amount of $\mathrm{Ca}^{2+}$ released during the abrupt rising phase of spikes. At shorter $\mathrm{IP}_{3} \mathrm{R}-\mathrm{MCU}$ distances, the mitochondria become almost saturated before the abrupt rising phase, and thus during the abrupt rising phase more of the $\mathrm{Ca}^{2+}$ ions released from the ER diffuse more into cytosol, generating a higher amplitude of $\left[\mathrm{Ca}^{2+}\right]_{\text {Cyt. }}$ However, the change in the total amount of $\mathrm{Ca}^{2+}$ release from the ER seen with decreasing distance is mainly determined by the release of $\mathrm{Ca}^{2+}$ occurring during the decay phase of spike. The enhanced inhibitory effect of higher amplitude $\left[\mathrm{Ca}^{2+}\right]_{\mathrm{Cyt}}$ spikes on $\mathrm{IP}_{3} \mathrm{R}$ dynamics in turn leads to a shortening of the decay time of the spikes, resulting in a decrease in the total $\mathrm{Ca}^{2+}$ amount released from ER with decreased $\mathrm{IP}_{3} \mathrm{R}-\mathrm{MCU}$ distance.

The existence of high $\left[\mathrm{Ca}^{2+}\right]_{\text {Mic }}$ in microdomains has been put forward as one way to resolve the apparent paradox that even though the $\mathrm{Ca}^{2+}$ affinity of the MCU is low $\left(\mathrm{K}_{\mathrm{d}}\right.$ of 10-20 $\left.\mu \mathrm{M}\right)$ highly efficient mitochondrial $\mathrm{Ca}^{2+}$ uptake still occurs under physiological conditions with low micromolar global $\left[\mathrm{Ca}^{2+}\right]_{\mathrm{Cyt}^{3}}{ }^{3}$. However, an intriguing question related to the role of the microdomain is the distance between the ER and mitochondria that would be required to control distinct cellular processes. The distance from the ER membrane to OMM was originally estimated to be in excess of $100 \mathrm{~nm}^{16}$, recently it has been suggested that this distance could be in the order of $30 \mathrm{~nm}^{15,55}$. A key prediction of our model is that the optimal distance between the $\mathrm{IP}_{3} \mathrm{R}$ and MCU is about $30-85 \mathrm{~nm}$. This arises when parameters for $\left[\mathrm{IP}_{3}\right]$ and $\left[\mathrm{Ca}^{2+}\right]$ are derived from the experimental observations that $\mathrm{Ca}^{2+}$ oscillations generally occur for intermediate values of $\mathrm{IP}_{3}{ }^{50}$ and that physiological $\left[\mathrm{Ca}^{2+}\right]_{\text {Cyt }}$ amplitudes seldom exceed $3.5 \mu \mathrm{M}$ in living cells $\mathrm{s}^{38,48}$, which are illustrated in Fig. 7. Considering that the thickness between OMM and IMM is around $20 \mathrm{~nm}^{56}$, our model predicts that the optimal gap between the ER membrane and OMM should be approximately $10-65 \mathrm{~nm}$, which is in good agreement with measurements obtained via electron microscopy and tomography ${ }^{15,31,55}$.

Interestingly, our simulation also provides a reason for why MCUs need to be located $\sim 20 \mathrm{~nm}$ away from the OMM. In experiment, elevations in the magnitude of $\left[\mathrm{Ca}^{2+}\right]_{\mathrm{Cyt}}$ during typical agonist induced responses could lead to a triggering of $\left[\mathrm{Ca}^{2+}\right]_{\mathrm{Cyt}}$-induced apoptosis ${ }^{51}$. Maintaining a distance between IMM and OMM of $20 \mathrm{~nm}$ may present a defense mechanism to keep the global $\left[\mathrm{Ca}^{2+}\right]_{\text {Cyt }}$ at a small physiological range. Our model highlights the importance of the $\mathrm{IP}_{3} \mathrm{R}-\mathrm{MCU}$ distance and suggests that potential pathological mechanisms for generating elevated $\left[\mathrm{Ca}^{2+}\right]_{\mathrm{Cyt}}$ and leading to possibly $\left[\mathrm{Ca}^{2+}\right]_{\mathrm{Cyt}}$-induced apoptosis ${ }^{6,51}$ would be found in disorders in which the optimal distance between the ER and mitochondria is disturbed. Considering that when untethered to the ER, mitochondria can be highly mobile organelles ${ }^{54}$ and that little is known of the physiological stimuli governing the distance between the ER and mitochondria, or how the tethers between the ER and mitochondria function or are disrupted during pathology, future research elucidating how the $\mathrm{IP}_{3} \mathrm{R}-\mathrm{MCU}$ distance is maintained and controlled is essential.

Finally, we discuss the advantages and limitations of our model. First, the previous published models typically simulated MCU either by a simple Hill equation ${ }^{26,29}$ or by the Monod-Wyman-Changeux type allosteric regulation ${ }^{24,27,28}$. In contrast to these models, we introduced a mechanistic kinetic model to discuss in detail the binding and unbinding processes of $\mathrm{Ca}^{2+}$ to MCU. Second, the numerical simulation about the peak values of $\left[\mathrm{Ca}^{2+}\right]_{\mathrm{ER}}$ or/and $\left[\mathrm{Ca}^{2+}\right]_{\mathrm{Mt}}$ were usually underestimated in most of the models ${ }^{24,26-30}$. For example, the concentration of free $\mathrm{Ca}^{2+}$ in the ER is typically in the range of a few hundred micromolars. Our model is capable of reproducing the observed magnitudes of $\left[\mathrm{Ca}^{2+}\right]_{\mathrm{Cyt}},\left[\mathrm{Ca}^{2+}\right]_{\mathrm{ER}}$ and $\left[\mathrm{Ca}^{2+}\right]_{\mathrm{Mt}}$.

In 2013, Szopa et al. suggested a model to explicitly take into account the existence of $\mathrm{Ca}^{2+}$ microdomain between the ER and mitochondria to discuss the mitochondrial $\mathrm{Ca}^{2+}$ uptake ${ }^{29}$. However, the assumption in the model that MCU directly senses the $\left[\mathrm{Ca}^{2+}\right]_{\mathrm{ER}}$ may be not very appropriate, particularly in view of the existing sharp $\mathrm{Ca}^{2+}$ gradients in the microdomain against the distance between the $\mathrm{IP}_{3} \mathrm{R}$ and MCU. Previously, there are mainly two basic ways to handle $\mathrm{Ca}^{2+}$ microdomain in the whole-cell models. The first approach involved the separation of a specified small region from the cell. But this subspace is simply treated as another well-mixed compartment ${ }^{57,58}$, and thus this approach cannot capture the fact of sharp $\mathrm{Ca}^{2+}$ concentration gradients in the microdomain $^{43,44}$. Sneyd et al. used an alternative approach to divide the cell into a few separate domains, connected by many boundary fluxes ${ }^{59,60}$. Although this is a powerful approach, it greatly increases the complexity of the model, leading to extreme computational difficulties.

Different from these methods, a new approach has been suggested in the present paper. For simplicity, all the $\mathrm{IP}_{3} \mathrm{Rs}$ dynamics and SERCA are determined by the bulk $\left[\mathrm{Ca}^{2+}\right]_{\mathrm{Cyt}}$. As a result, the bulk $\mathrm{Ca}^{2+}$ concentrations in cytosol, ER and mitochondria can be examined in deterministic ODE which actually assuming that the cytosolic, ER and mitochondrial compartments are mixed homogenously. Upon such well mixed compartments, a microdomain is specifically considered to discuss the MCU dynamics which is crucial for mitochondrial $\mathrm{Ca}^{2+}$ uptake. The microdomain consists of a cluster of $\mathrm{IP}_{3} \mathrm{Rs}$ and a MCU separated at a short distance. Treated as a point release source for the clustered $\mathrm{IP}_{3} \mathrm{Rs}$ which dynamics is controlled by bulk $\left[\mathrm{Ca}^{2+}\right]_{\mathrm{Cyt}}$, a sharp distribution of $\left[\mathrm{Ca}^{2+}\right]_{\mathrm{Mic}}$ can be built up in the microdomain. Each MCU responds to the local high $\left[\mathrm{Ca}^{2+}\right]_{\mathrm{Mic}}$ generated by the clustered $\mathrm{IP}_{3} \mathrm{Rs}$, rather than the bulk $\left[\mathrm{Ca}^{2+}\right]_{\mathrm{Cyt}}$. As a result, this method avoids the simulation of the $\mathrm{Ca}^{2+}$ diffusion in microdomain between the ER membrane and IMM.

Peglow et al..$^{30}$ discussed a three-dimensional model to analyze the influence of the distance between mitochondria and the CRAC channel on the plasma membrane, which is responsible for $\mathrm{Ca}^{2+}$ influx from the outside of the cell, on global $\mathrm{Ca}^{2+}$ oscillation. They confirmed that the relative position between mitochondria and the CRAC channels controls the global $\mathrm{Ca}^{2+}$ signal. Their simulation results showed that close mitochondria will lower the microdomain $\left[\mathrm{Ca}^{2+}\right]$ right at the CRAC channels and prevent the $\mathrm{Ca}^{2+}$-dependent inactivation of CRAC channels, leading to higher $\mathrm{Ca}^{2+}$ influx and thereby increasing global $\left[\mathrm{Ca}^{2+}\right]_{\mathrm{Cyt}}$. They found that the global $\left[\mathrm{Ca}^{2+}\right]_{\text {Cyt }}$ monotonously changes with the mitochondria-CRAC distance from 0.1 to $2 \mu \mathrm{m}$. A similar result is obtained in our model at $\mathrm{r}$ $>\mathrm{r}_{\mathrm{crt}}$.

As a fact, our model does not realistically consider the spatial structure and so many important factors of $\mathrm{Ca}^{2+}$ signaling have been ignored. In the model the microdomain is modeled as a radially symmetric hemisphere and so the linearized reaction-diffusion equation has been applied to obtain a simple expression for $\left[\mathrm{Ca}^{2+}\right]_{\mathrm{Mic}}$. The mitochondrial boundary is actually ignored. One may expect that the mitochondrial boundary effect may modulate the sharp $\left[\mathrm{Ca}^{2+}\right]_{\mathrm{Mic}}$ distribution. The $\mathrm{Ca}^{2+}$ release from the clustered $\mathrm{IP}_{3} \mathrm{Rs}$ are treated as the point release source, which is correct for far away MCU. But if $\mathrm{MCU}$ is too close to $\mathrm{IP}_{3} \mathrm{Rs}$, a better treatment is to consider the spatial distribution of $\mathrm{IP}_{3}$ Rs. The model also assumes that OMM has no effect on the $\mathrm{Ca}^{2+}$ diffusion as it has high permeability to $\mathrm{Ca}^{2+} . \mathrm{A}$ 
better MCU model should also consider the regulation effect of MICU2 on the MCU channel activity. Our model is primarily designed for non-excitable cells, i.e. a 'closed' cell model, ignoring the $\mathrm{Ca}^{2+}$ exchange between cytosol and extracellular medium through the plasma membrane. Thus, a more realistic $\mathrm{Ca}^{2+}$ model should be considered in the future. However, despite oversimplification in some details, we believe that the present model is useful and may provide us some insights on how the crosstalk between the ER and mitochondria modulates $\mathrm{Ca}^{2+}$ signals in living cells.

1. Berridge, M. J., Bootman, M. D. \& Roderick, H. L. Calcium signalling: dynamics, homeostasis and remodelling. Nat. Rev. Mol. Cell Bio. 4, 517-529 (2003).

2. Parekh, A. B. Decoding cytosolic $\mathrm{Ca}^{2+}$ oscillations. Trends Biochem. Sci. 36, 78-87 (2011).

3. Contreras, L., Drago, I., Zampese, E. \& Pozzan, T. Mitochondria: the calcium connection. BBA-Bioenergetics 1797, 607-618 (2010).

4. Rizzuto, R., Brini, M., Murgia, M. \& Pozzan, T. Microdomains with high $\mathrm{Ca}^{2+}$ close to $\mathrm{IP}_{3}$-sensitive channels that are sensed by neighboring mitochondria. Science 262, 744-747 (1993).

5. Hajnóczky, G., Robb-Gaspers, L. D., Seitz, M. B. \& Thomas, A. P. Decoding of cytosolic calcium oscillations in the mitochondria. Cell 82, 415-424 (1995).

6. Rizzuto, R., De Stefani, D., Raffaello, A. \& Mammucari, C. Mitochondria as sensors and regulators of calcium signalling. Nat. Rev. Mol. Cell Bio. 13, 566-578 (2012).

7. Giacomello, M. et al. $\mathrm{Ca}^{2+}$ Hot Spots on the Mitochondrial Surface Are Generated by $\mathrm{Ca}^{2+}$ Mobilization from Stores, but Not by Activation of Store-Operated $\mathrm{Ca}^{2+}$ Channels. Mol. Cell 38, 280-290 (2010).

8. Csordás, G. et al. Imaging interorganelle contacts and local calcium dynamics at the ER-mitochondrial interface. Mol. Cell 39, 121-132 (2010).

9. Jouaville, L. S., Ichas, F., Holmuhamedov, E. L., Camacho, P. \& Lechleiter, J. D. Synchronization of calcium waves by mitochondrial substrates in Xenopus laevis oocytes. Nature 377, 438-441 (1995).

10. Vay, L. et al. Modulation of $\mathrm{Ca}^{2+}$ release and $\mathrm{Ca}^{2+}$ oscillations in HeLa cells and fibroblasts by mitochondrial $\mathrm{Ca}^{2+}$ uniporter stimulation. J. Physiol. 580, 39-49 (2007).

11. Olson, M. L., Chalmers, S. \& McCarron, J. G. Mitochondrial $\mathrm{Ca}^{2+}$ uptake increases $\mathrm{Ca}^{2+}$ release from inositol 1, 4, 5-trisphosphate receptor clusters in smooth muscle cells. J. Biol. Chem. 285, 2040-2050 (2010).

12. Boitier, E., Rea, R. \& Duchen, M. R. Mitochondria exert a negative feedback on the propagation of intracellular $\mathrm{Ca}^{2+}$ waves in rat cortical astrocytes. J. Cell Biol. 145, 795-808 (1999).

13. Hajnóczky, G., Hager, R. \& Thomas, A. P. Mitochondria suppress local feedback activation of inositol 1, 4, 5-trisphosphate receptors by $\mathrm{Ca}^{2+}$. J. Biol. Chem. 274, 14157-14162 (1999).

14. Olson, M. L., Chalmers, S. \& McCarron, J. G. Mitochondrial organization and $\mathrm{Ca}^{2+}$ uptake. Biochem. Soc. Trans. 40, 158-167 (2012).

15. Csordás, G. et al. Structural and functional features and significance of the physical linkage between ER and mitochondria. J. Cell Biol. 174, 915-921 (2006).

16. de Brito, O. M. \& Scorrano, L. An intimate liaison: spatial organization of the endoplasmic reticulum-mitochondria relationship. EMBO J. 29, 2715-2723 (2010).

17. Williams, G. S., Boyman, L., Chikando, A. C., Khairallah, R. J. \& Lederer, W Mitochondrial calcium uptake. Proceedings of the National Academy of Sciences 110, 10479-10486 (2013).

18. Meyer, T. \& Stryer, L. Molecular model for receptor-stimulated calcium spiking. Proc. Nat. Acad. Sci.USA 85, 5051-5055 (1988).

19. Li, Y. X. \& Rinzel, J. Equations for InsP $\mathrm{P}_{3}$ Receptor-mediated $\left[\mathrm{Ca}^{2+}\right]_{\mathrm{i}}$ Oscillations Derived from a Detailed Kinetic Model: A Hodgkin-Huxley Like Formalism. J. Theor. Biol. 166, 461-473 (1994).

20. Shuai, J. W. \& Jung, P. Stochastic Properties of $\mathrm{Ca}^{2+}$ Release of Inositol 1, 4, 5 Trisphosphate Receptor Clusters. Biophys. J. 83, 87-97 (2002).

21. Shuai, J. W. \& Jung, P. Optimal ion channel clustering for intracellular calcium signaling. Proc. Nat. Acad. Sci.USA 100, 506-510 (2003).

22. Rüdiger, S., Shuai, J. W. \& Sokolov, I. Law of mass action, detailed balance, and the modeling of calcium puffs. Phys. Rev. Lett. 105, 048103 (2010).

23. Rüdiger, S. Stochastic models of intracellular calcium signals. Phys. Rep. 534 39-87 (2014).

24. Cortassa, S., Aon, M. A., Marbán, E., Winslow, R. L. \& O’Rourke, B. An integrated model of cardiac mitochondrial energy metabolism and calcium dynamics. Biophys. J. 84, 2734-2755 (2003).

25. Dash, R. K., Qi, F. \& Beard, D. A. A biophysically based mathematical model for the kinetics of mitochondrial calcium uniporter. Biophys. J. 96, 1318-1332 (2009).

26. Marhl, M., Haberichter, T., Brumen, M. \& Heinrich, R. Complex calcium oscillations and the role of mitochondria and cytosolic proteins. Biosystems 57, 75-86 (2000).

27. Fall, C. P \& Keizer, J. E. Mitochondrial Modulation of Intracellular $\mathrm{Ca}^{2+}$ Signaling. J. Theor. Biol. 210, 151-165 (2001)

28. Ndiaye, D. et al. Characterization of the Effect of the Mitochondrial Protein Hint2 on Intracellular $\mathrm{Ca}^{2+}$ dynamics. Biophys. J. 105, 1268-1275 (2013).
29. Szopa, P., Dyzma, M. \& Kazmierczak, B. Membrane associated complexes in calcium dynamics modelling. Phys. Biol. 10, 035004 (2013).

30. Peglow, M., Niemeyer, B. A., Hoth, M. \& Rieger, H. Interplay of channels, pumps and organelle location in calcium microdomain formation. New J. Phys. 15, 055022 (2013).

31. Moreau, B., Nelson, C. \& Parekhm, A. B. Biphasic regulation of mitochondrial $\mathrm{Ca}^{2+}$ uptake by cytosolic $\mathrm{Ca}^{2+}$ concentration. Curr. Biol. 16, 1672-1677 (2006).

32. Tang, S. et al. Design and application of a class of sensors to monitor $\mathrm{Ca}^{2+}$ dynamics in high $\mathrm{Ca}^{2+}$ concentration cellular compartments. Proc. Nat. Acad. Sci.USA 108, 16265-16270 (2011).

33. Csordás, G. et al. MICU1 Controls Both the Threshold and Cooperative Activation of the Mitochondrial $\mathrm{Ca}^{2+}$ Uniporter. Cell Metab. 17, 976-987 (2013).

34. McCarron, J. G., Olson, M. L. \& Chalmers, S. Mitochondrial regulation of cytosolic $\mathrm{Ca}^{2+}$ signals in smooth muscle. Pflügers Arch.,-EJP 464, 51-62 (2012).

35. Gunter, T. E. \& Sheu, S. S. Characteristics and possible functions of mitochondrial $\mathrm{Ca}^{2+}$ transport mechanisms. BBA-Bioenergetics 1787, 1291-1308 (2009).

36. Mallilankaraman, K. et al. MICU1 Is an Essential Gatekeeper for MCU-Mediated Mitochondrial $\mathrm{Ca}^{2+}$ Uptake that Regulates Cell Survival. Cell 151, 630-644 (2012).

37. Baughman, J. M. et al. Integrative genomics identifies MCU as an essential component of the mitochondrial calcium uniporter. Nature 476, 341-345 (2011).

38. De Stefani, D., Raffaello, A., Teardo, E., Szabò, I. \& Rizzuto, R. A forty-kilodalton protein of the inner membrane is the mitochondrial calcium uniporter. Nature 476, 336-340 (2011).

39. Raffaello, A. et al. The mitochondrial calcium uniporter is a multimer that can include a dominant-negative pore-forming subunit. EMBO J. 32, 2362-2376 (2013).

40. Csordás, G., Thomas, A. P. \& Hajnóczky, G. Quasi-synaptic calcium signal transmission between endoplasmic reticulum and mitochondria. EMBO J. 18 96-108 (1999).

41. Taufiq-Ur-Rahman, A. S., Falcke, M. \& Taylor, C. W. Clustering of InsP receptors by $\mathrm{InsP}_{3}$ retunes their regulation by $\mathrm{InsP}_{3}$ and $\mathrm{Ca}^{2+}$. Nature 458, 655-659 (2009).

42. Dickinson, G. D., Swaminathan, D. \& Parker, I. The probability of triggering calcium puffs is linearly related to the number of inositol trisphosphate receptors in a cluster. Biophys. J. 102, 1826-1836 (2012).

43. Vais, H., Foskett, J. K. \& Mak, D.-O. D. Unitary $\mathrm{Ca}^{2+}$ current through recombinant type $3 \mathrm{InsP} 3$ receptor channels under physiological ionic conditions. J. Gen. Physiol. 136, 687-700 (2010).

44. Smith, G. D. Analytical steady-state solution to the rapid buffering approximation near an open $\mathrm{Ca}^{2+}$ channel. Biophys. J. 71, 3064-3072 (1996).

45. Neher, E. Vesicle Pools and $\mathrm{Ca}^{2+}$ Microdomains: New Tools for Understanding Their Roles in Neurotransmitter Release. Neuron 20, 389-399 (1998).

46. Arnaudeau, S., Kelley, W. L., Walsh, J. V. \& Demaurex, N. Mitochondria recycle $\mathrm{Ca}^{2+}$ to the endoplasmic reticulum and prevent the depletion of neighboring endoplasmic reticulum regions. J. Biol. Chem. 276, 29430-29439 (2001).

47. Ishii, K., Hirose, K. \& Iino, M. $\mathrm{Ca}^{2+}$ shuttling between endoplasmic reticulum and mitochondria underlying $\mathrm{Ca}^{2+}$ oscillations. EMBO Rep. 7, 390-396 (2006).

48. Kornmann, B. The molecular hug between the ER and the mitochondria. Curr. Opin. Cell Biol. 25, 1-6 (2013).

49. Berridge, M. J. Calcium oscillations. J. Biol. Chem. 265, 9583-9586 (1990).

50. Camacho, P. \& Lechleiter, J. D. Increased frequency of calcium waves in Xenopus laevis oocytes that express a calcium-ATPase. Science 260, 226-229 (1993).

51. Kim, I., Xu, W. J. \& Reed, J. C. Cell death and endoplasmic reticulum stress: disease relevance and therapeutic opportunities. Nat. Rev. Drug Discov. 7, 1013-1030 (2008).

52. Kaftan, E. J., Xu, T., Abercrombie, R. F. \& Hille, B. Mitochondria shape hormonally induced cytoplasmic calcium oscillations and modulate exocytosis. J. Biol. Chem. 275, 25465-25470 (2000).

53. Pacher, P., Csordás, G., Schneider, T. G. \& Hajnóczky, G. Quantification of calcium signal transmission from sarco-endoplasmic reticulum to the mitochondria. Journal Physiol. 529, 553-564 (2000).

54. Wang, X. \& Schwarz, T. L. The Mechanism of $\mathrm{Ca}^{2+}$-Dependent Regulation of Kinesin-Mediated Mitochondrial Motility. Cell 136, 163-174 (2009).

55. Friedman, J. R., Lackner, L. L, West, M., DiBenedetto, J. R., Nunnari, J. \& Voeltz, G. K. ER tubules mark sites of mitochondrial division. Science 334, 358-362 (2011).

56. Walther, P., Höhn, K. \& Krisp, H. What is the true size of the mitochondrial intermembrane space? A study using high-pressure freezing and STEM tomography. Proceedings of MC 2, 49-50 (2009).

57. Jafri, M. S., Rice, J. J. \& Winslow, R. L. Cardiac $\mathrm{Ca}^{2+}$ dynamics: The roles of ryanodine receptor adaptation and sarcoplasmic reticulum load. Biophys. J. 74, 1149-1168 (1998).

58. LeBeau, A. P., Van Goor, F., Stojilkovic, S. S. \& Sherman A. Modeling of membrane excitability in gonadotropin-releasing hormone-secreting hypothalamic neurons regulated by $\mathrm{Ca}^{2+}$ mobilizing and adenylyl cyclasecoupled receptors. J. Neurosci. 20, 9290-9297 (2000).

59. Higgins, E. R. et al. Modelling calcium microdomains using homogenisation. J. Theor. Biol. 247, 623-644 (2007). 
60. Means, S. A. \& Sneyd, J. Spatio-temporal calcium dynamics in pacemaking units of the interstitial cells of Cajal. J. Theor. Biol. 267, 137-152 (2010).

\section{Acknowledgments}

We would like to acknowledge many useful conversations with George Dickinson, Ian Parker and Jeffery Lock in University of California, Irvine. We also thank Ke Jiang and Yu Jiang in Xiamen University for help with numerical simulations. This work was supported by the China National Funds for Distinguished Young Scholars under grant 11125419, the National Natural Science Foundation of China under grant 31370830, the Fujian Province Funds for Leading Scientist in Universities and ICAM branches cost sharing fund.

\section{Author contributions}

H.Q. and J.S. conceived and designed the model. H.Q. performed the numerical simulations. L.L. contributed to the writing of the programs. H.Q. and J.S. wrote the paper.

\section{Additional information}

Supplementary information accompanies this paper at http://www.nature.com/ scientificreports

Competing financial interests: The authors declare no competing financial interests.

How to cite this article: Qi, H., Li, L. \& Shuai, J. Optimal microdomain crosstalk between endoplasmic reticulum and mitochondria for $\mathrm{Ca}^{2+}$ oscillations. Sci. Rep. 5, 7984;

DOI:10.1038/srep07984 (2015).

(c) (1) () () This work is licensed under a Creative Commons Attribution-NonCommercialNoDerivs 4.0 International License. The images or other third party material in this article are included in the article's Creative Commons license, unless indicated otherwise in the credit line; if the material is not included under the Creative Commons license, users will need to obtain permission from the license holder in order to reproduce the material. To view a copy of this license, visit http:// creativecommons.org/licenses/by-nc-nd/4.0/ 